\title{
THE METABOLISM OF GLUCOSE AND ELECTROLYTES IN DIABETIC ACIDOSIS ${ }^{1}$
}

\author{
By DONALD W. SELDIN AND ROBERT TARAIL 2 \\ (From the Department of Internal Medicine, Yale University School of Medicine, \\ New Haven, Conn.)
}

(Submitted for publication September 23, 1949; accepted, January 9, 1950)

\section{INTRODUCTION}

The role of glucose in the treatment of diabetic acidosis has, until recently $(1,2)$, been evaluated largely in terms of the question whether glucose, administered early when insulin action is minimal, could promote the utilization of carbohydrate and retard ketosis (3-9). Proponents of the early use of glucose base their advocacy on the demonstration, in normal $(10,11)$ and depancreatized $(12$, 13) dogs, and in normal ( 7$)$ and diabetic $(3,9$, 14) human subjects, that hyperglycemia, all other things being equal, accelerates the peripheral oxidation of carbohydrate and the deposition of liver glycogen, thereby tending to suppress ketosis (6, $7)$. The relevance of these observations for clinical diabetes has been established by Mirsky and his associates (9), who were able to stop severe diabetic ketosis by the administration of massive amounts of glucose alone.

But hyperglycemia, arising from endogenous sources or maintained or induced by injections of glucose, profoundly influences the volume and composition of the extracellular fluid, exchanges of phosphorus and potassium, and the excretion of water and electrolytes, as well as the metabolism of carbohydrate. These metabolic and osmotic properties of glucose, especially in the context of diabetic acidosis, must be carefully evaluated if its role in the development and treatment of this disorder is to be adequately described.

The present study is an attempt to contribute toward this end by analyzing the exchanges and excretion of carbohydrate, electrolytes, and water during consecutive short periods before and dur-

1 A preliminary report of this investigation was included in the Proceedings of the Forty-First Annual Meeting of the American Society for Clinical Investigation ( $\mathrm{J}$. Clin. Invest., 1949, 28, 810).

2 Work done during the tenure of a Life Insurance Medical Research Fund Fellowship.

Present address : Department of Biochemistry, Boston University School of Medicine, Boston, Massachusetts. ing treatment, and by comparing the effects of the administration of massive and small quantities of glucose early in the course of diabetic acidosis.

\section{EXPERIMENTAL PROCEDURE}

Seventeen studies of 15 patients were completed (M.Br. and A.F. were studied on two separate occasions). All patients were adults; W.R. was the only male. On admission the usual chemical and clinical evidences of diabetic acidosis were present. In eight studies a short, accurately timed urine (pre-treatment urine) was obtained before blood was drawn and therapy instituted.

The studies are divided into two groups. In one group of ten cases (Tables I-III) small or moderate amounts of glucose were injected as a 5 or 10 per cent solution. A second group of seven cases (Table IV) were given large amounts of glucose in a concentration of 20 per cent or more. Tables I and IV summarize the amounts of insulin and various repair substances administered during each period. Immediately after the initial blood was drawn for analysis, 50 units of regular insulin were injected subcutaneously. In the succeeding four to five hours, a total of about 3 to 4 liters of normal saline was administered and injections of insulin were continued at a rate averaging 37 units/hour. The subsequent administration of insulin and saline varied widely from patient to patient, depending upon the clinical response. Potassium salts were given to five patients (Table I, M.C., B.K., A.F.1, M.B. and B.H.) when the concentration of serum potassium had fallen to $3.5 \mathrm{meq}$./liter or less. If nausea had been overcome, potassium was given orally as $\mathrm{KCl}$, about $7.5 \mathrm{gms}$. being added to a liter of milk or orange juice which was drunk at a rate approximating $250 \mathrm{cc}$./hour. If nausea was present, potassium was injected intravenously (either as $\mathrm{KCl}$ or as a mixture of $\mathrm{K}_{2} \mathrm{HPO}_{4}$ and $\mathrm{KH}_{2} \mathrm{PO}_{4}$ of $\mathrm{pH} 7.4$ ) dissolved in normal saline or 5 per cent glucose at a rate not exceeding 20 meq./hour. When evidences of peripheral vascular collapse were present, blood and occasionally salt-poor human albumin were promptly injected. The nitrogen and electrolyte content of these substances are included under the Intake column in Table I.

The four deaths in this series were all in patients who were critically ill at the time the study was instituted. Three of these patients-H.T., M.B., B.H.-had been in profound peripheral vascular collapse for one or more days, and were moribund on admission. A.P. was admitted with uncontrolled hyperthyroidism and an acute vascular disease resembling periarteritis nodosa; these 
complications in a patient with severe diabetic acidosis could explain the fatal outcome, although the extremely low serum potassium (even in the absence of cardiac or neurological findings of hypokaliemia) may have been a contributory factor. M.B. received a large amount of glucose in the latter part of period C (Table I) because of an erroneous report of a low blood sugar. Since she was in profound vascular collapse and moribund long before the injection, it is difficult to evaluate the relation of this admittedly adverse procedure to her death. Though none of the fatal cases are suitable for the evaluation of treatment, since they probably would have died irrespective of the therapeutic regime, they are neverthe- less reported here because they exemplify in the extreme disturbances present to a lesser degree in the other cases.

\section{METHODS AND CALCULATIONS}

Glucose was determined, in whole blood, by the method of Benedict, using zinc filtrates $(15,16)$, and in urine by the method of Somogyi (17). Inorganic phosphorus was determined by the method of Fiske and Subbarow (18) as modified for the photo-electric colorimeter. Other methods used were identical with those previously reported from this laboratory $(19,20)$.

Balance data were calculated by the methods previously reported from this department $(21,22)$ and by

TABLE I

Intake and external balance during treatment of diabetic acidosis

\begin{tabular}{|c|c|c|c|c|c|c|c|c|c|c|c|c|c|c|c|c|}
\hline \multirow{2}{*}{ 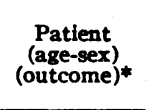 } & \multirow{2}{*}{ eriodt } & \multirow{2}{*}{ Duration } & \multicolumn{8}{|c|}{ Intake $\$$} & \multicolumn{6}{|c|}{ External balancell } \\
\hline & & & Insulin & $\mathrm{H}_{2} \mathrm{O}$ & $\mathrm{Cl}$ & $\mathrm{Na}$ & $\mathbf{K}$ & $\mathbf{P}$ & $\mathbf{N}$ & $\mathrm{CHO}$ & $\mathrm{Cl}$ & $\mathbf{N a}$ & $\mathbf{K}$ & $\mathbf{P}$ & $\mathbf{N}$ & Gluc. \\
\hline M. C. & $\begin{array}{l}\mathbf{A} \\
\mathbf{B} \\
\mathbf{C} \\
\mathbf{D} \\
\end{array}$ & $\begin{array}{c}\text { hours } \\
0-7.50 \\
7.50-13.50 \\
13.50-17.50 \\
17.50-41.50 \\
\end{array}$ & $\begin{array}{c}\text { units } \\
230 \\
100 \\
50 \\
45 \\
\end{array}$ & $\begin{array}{c}c c . \\
5250 \\
2375 \\
2130 \\
2635 \\
\end{array}$ & $\begin{array}{c}\text { meq. } \\
368 \\
123 \\
222 \\
170 \\
\end{array}$ & \begin{tabular}{r|} 
meq. \\
368 \\
123 \\
196 \\
44 \\
\end{tabular} & $\begin{array}{r}\text { meq. } \\
4 \\
0 \\
50 \\
185 \\
\end{array}$ & $\begin{array}{c}m g . \\
100 \\
0 \\
267\end{array}$ & $\begin{array}{r}\text { gms. } \\
0.2 \\
0 \\
1.7 \\
10.1 \\
\end{array}$ & $\begin{array}{r}\text { gms. } \\
200 \\
97 \\
176 \\
33\end{array}$ & $\begin{array}{c}\text { meq. } \\
+337 \\
+72 \\
+172 \\
+191 \\
\end{array}$ & $\begin{array}{r}\text { meq. } \\
+312 \\
+96 \\
+174 \\
+102 \\
\end{array}$ & $\begin{array}{l}\text { meq. } \\
=27 \\
=17 \\
+36 \\
+119\end{array}$ & \begin{tabular}{|c|}
$m g$. \\
$=490$ \\
+149 \\
+155
\end{tabular} & $\begin{array}{l}g m s . \\
-3.0 \\
-3.1 \\
-0.8 \\
+0.3 \\
\end{array}$ & $\begin{array}{l}g_{m s .} \\
+124 \\
+46 \\
+140 \\
+162 \\
\end{array}$ \\
\hline B. $\mathrm{K}$ (45 \&) & $\begin{array}{l}\text { Prt. } \\
\text { A } \\
\text { B } \\
\text { C } \\
\text { D }\end{array}$ & $\begin{array}{c}0-0.87 \\
0.87-2.35 \\
2.35-5.62 \\
5.62-10.35 \\
10.35-22.35\end{array}$ & $\begin{array}{r}0 \\
120 \\
80 \\
55 \\
20\end{array}$ & $\begin{array}{r}0 \\
1275 \\
2225 \\
1975 \\
1000\end{array}$ & $\begin{array}{r}0 \\
154 \\
250 \\
135 \\
136\end{array}$ & $\begin{array}{r}0 \\
154 \\
250 \\
135 \\
.22\end{array}$ & $\begin{array}{r}\mathbf{0} \\
0 \\
0 \\
0 \\
149\end{array}$ & $\begin{array}{l}\mathbf{0} \\
0 \\
0 \\
0\end{array}$ & $\begin{array}{l}0 \\
0 \\
0 \\
0 \\
5.3\end{array}$ & $\begin{array}{r}0 \\
28 \\
60 \\
150 \\
98\end{array}$ & $\begin{array}{r}0 \\
+\quad 149 \\
+235 \\
+\quad 121 \\
+\quad 20\end{array}$ & $\begin{array}{r}-\quad 7 \\
+\quad 141 \\
+239 \\
+132 \\
+\quad 6\end{array}$ & $\begin{array}{ll}= & 7 \\
= & 8 \\
= & 6 \\
+117\end{array}$ & \begin{tabular}{ll|}
$=$ & 59 \\
$=$ & 75 \\
$=$ & 77 \\
- & 30
\end{tabular} & $\begin{array}{l}-0.5 \\
-0.8 \\
-1.8 \\
-1.3 \\
+1.8\end{array}$ & $\begin{array}{r}-3 \\
+23 \\
+48 \\
+148 \\
+96\end{array}$ \\
\hline A. Fil & $\begin{array}{l}\text { Prt. } \\
\text { A } \\
\text { B } \\
\text { C } \\
\text { D } \\
\text { E }\end{array}$ & $\begin{array}{c}0-0.62 \\
0.62-2.74 \\
2.74-4.89 \\
4.89-9.34 \\
9.34-33.34 \\
33.34-58.34\end{array}$ & $\begin{array}{r}0 \\
120 \\
60 \\
120 \\
40 \\
65\end{array}$ & \begin{tabular}{|r|}
1975 \\
1155 \\
2320 \\
4200 \\
3000 \\
\end{tabular} & $\begin{array}{r}0 \\
246 \\
116 \\
178 \\
242 \\
163\end{array}$ & $\begin{array}{r}00 \\
246 \\
116 \\
100 \\
131 \\
44\end{array}$ & $\begin{array}{r}0 \\
0 \\
0 \\
78 \\
111 \\
232\end{array}$ & $\begin{array}{l}\mathbf{0} \\
\mathbf{0} \\
\mathbf{0} \\
\mathbf{0} \\
\mathbf{0}\end{array}$ & $\begin{array}{c}0 \\
0 \\
0 \\
0 \\
0 \\
11.3\end{array}$ & $\begin{array}{r}0 \\
38 \\
41 \\
167 \\
315 \\
262\end{array}$ & $\begin{array}{rr} & 5 \\
+ & 149 \\
+ & 155 \\
+ & 88 \\
\pm & 58 \\
-276\end{array}$ & $\begin{array}{r}-\quad 12 \\
\pm 120 \\
\pm 140 \\
\pm \quad 42 \\
\pm \quad 28 \\
-\quad 244\end{array}$ & $\begin{array}{lr} & 5 \\
= & 15 \\
\overline{1} & 14 \\
+ & 9 \\
+106\end{array}$ & $\begin{array}{l}=\quad 55 \\
=184 \\
=114 \\
=109 \\
=109\end{array}$ & $\begin{array}{l}-0.4 \\
-1.2 \\
-1.7 \\
-2.4 \\
-4.5 \\
+5.3\end{array}$ & $\begin{array}{r}-9 \\
+\quad 8 \\
+11 \\
+119 \\
+309 \\
+247\end{array}$ \\
\hline W. R. & $\begin{array}{l}\text { Prt. } \\
\text { A } \\
\text { B } \\
\text { C } \\
\text { D }\end{array}$ & $\begin{array}{c}0-1.48 \\
1.48-3.28 \\
3.28-5.60 \\
5.60-9.03 \\
9.03-21.03\end{array}$ & $\begin{array}{r}0 \\
100 \\
40 \\
50 \\
70\end{array}$ & $\begin{array}{r}0 \\
1250 \\
1240 \\
1560 \\
2700\end{array}$ & $\begin{array}{r}0 \\
162 \\
131 \\
92 \\
308\end{array}$ & $\begin{array}{r}0 \\
162 \\
131 \\
92 \\
308\end{array}$ & $\begin{array}{l}\mathbf{0} \\
\mathbf{0} \\
\mathbf{0} \\
\mathbf{0} \\
\mathbf{0}\end{array}$ & $\begin{array}{l}0 \\
0 \\
0 \\
0 \\
0\end{array}$ & $\begin{array}{l}\mathbf{0} \\
\mathbf{0} \\
\mathbf{0} \\
\mathbf{0} \\
\mathbf{0}\end{array}$ & $\begin{array}{r}0 \\
20 \\
39 \\
96 \\
130\end{array}$ & $\begin{array}{r}-13 \\
+146 \\
+109 \\
+52 \\
+189\end{array}$ & $\begin{array}{r}\quad 22 \\
+139 \\
+118 \\
+73 \\
+242\end{array}$ & $\begin{array}{l}=9 \\
=\quad 7 \\
=\quad 8 \\
=11\end{array}$ & $\begin{array}{r}=142 \\
=116 \\
=\quad 59 \\
=\quad 50 \\
=110\end{array}$ & $\begin{array}{l}-1.4 \\
-1.6 \\
-1.6 \\
-2.1 \\
-4.1\end{array}$ & $\begin{array}{r}-14 \\
+\quad 6 \\
+23 \\
+69 \\
+110\end{array}$ \\
\hline $\begin{array}{l}\text { E. M.t } \\
(23 \%)\end{array}$ & $\begin{array}{l}\text { Prt. } \\
\text { A } \\
\text { B } \\
\text { C }\end{array}$ & $\begin{array}{c}0-1.05 \\
1.05-3.55 \\
3.55-6.28 \\
6.28-11.25\end{array}$ & $\begin{array}{r}0 \\
190 \\
50 \\
55\end{array}$ & $\begin{array}{r}0 \\
2040 \\
1215 \\
2075 \\
\end{array}$ & $\begin{array}{r}0 \\
276 \\
103 \\
125 \\
\end{array}$ & $\begin{array}{r}0 \\
281 \\
108 \\
135 \\
\end{array}$ & $\begin{array}{l}0 \\
1 \\
0 \\
1\end{array}$ & $\begin{array}{r}0 \\
5 \\
5 \\
10\end{array}$ & $\begin{array}{l}0 \\
1.5 \\
1.3 \\
2.8\end{array}$ & $\begin{array}{r}0 \\
20 \\
50 \\
100\end{array}$ & $\begin{array}{r}-\quad 1 \\
+\quad 255 \\
+\quad 52 \\
+\quad 58\end{array}$ & $\begin{array}{r}+\quad 1 \\
+250 \\
+56 \\
+\quad 90\end{array}$ & $\begin{array}{ll}= & 1 \\
= & 6 \\
= & 5\end{array}$ & $\begin{array}{r}=43 \\
=\quad 221 \\
=\quad 89 \\
=\quad 37\end{array}$ & $\begin{array}{l}-2.0 \\
+0.3 \\
-0.2 \\
+0.7\end{array}$ & $\begin{array}{l}-4 \\
\overline{7} \\
+21 \\
+49\end{array}$ \\
\hline $\begin{array}{c}\text { M.N.\$ } \\
(76 \%)\end{array}$ & $A$ & $\begin{array}{c}0-2.08 \\
2.08-5.08 \\
5.08-13.93\end{array}$ & $\begin{array}{r}130 \\
60 \\
30\end{array}$ & \begin{tabular}{|l|}
1340 \\
2200 \\
\end{tabular} & $\begin{array}{l}162 \\
196 \\
119 \\
\end{array}$ & $\begin{array}{l}172 \\
206 \\
119 \\
\end{array}$ & $\begin{array}{l}1 \\
1 \\
0\end{array}$ & $\begin{array}{r}10 \\
10 \\
0\end{array}$ & $\begin{array}{l}2.8 \\
2.8 \\
0\end{array}$ & $\begin{array}{r}20 \\
30 \\
143\end{array}$ & $\begin{array}{r}+134 \\
+159 \\
+\quad 70\end{array}$ & $\begin{array}{r}+137 \\
+166 \\
+\quad 87\end{array}$ & $\begin{array}{l}=9 \\
=11 \\
=15\end{array}$ & $\begin{array}{ll}= & 47 \\
= & 40 \\
- & 53\end{array}$ & $\begin{array}{l}+1.8 \\
+1.2 \\
-3.0\end{array}$ & $\begin{array}{l}+6 \\
+16 \\
+135\end{array}$ \\
\hline A. $\begin{array}{c}\text { P. di } \\
(52 \%)\end{array}$ & $\mathbf{A}$ & $0-12.00$ & 140 & 8900 & 848 & 848 & $\mathbf{0}$ & 0 & 0 & 305 & +623 & +679 & -18 & & -5.4 & +256 \\
\hline H. T. dif & A & $\begin{array}{r}0-1.83 \\
1.83-5.47\end{array}$ & $\begin{array}{l}100 \\
180\end{array}$ & \begin{tabular}{|l|}
1725 \\
3100 \\
\end{tabular} & $\begin{array}{l}257 \\
417\end{array}$ & $\begin{array}{l}264 \\
431\end{array}$ & $\begin{array}{l}1 \\
1\end{array}$ & $\begin{array}{r}7 \\
13\end{array}$ & $\begin{array}{l}2.0 \\
3.6\end{array}$ & $\begin{array}{r}0 \\
80\end{array}$ & $\begin{array}{l}+252 \\
+396 \\
\end{array}$ & $\begin{array}{r}+258 \\
+412\end{array}$ & {$\left[\begin{array}{r}0 \\
-\quad 1\end{array}\right]$} & $\begin{array}{r}-\quad 5 \\
-\quad 0 \\
\end{array}$ & $\begin{array}{l}+1.9 \\
+3.3\end{array}$ & $\overline{+}{ }^{2}$ \\
\hline M. B. dit & $\begin{array}{l}\mathbf{A} \\
\mathbf{B} \\
\mathbf{C}\end{array}$ & $\begin{array}{c}0-3.75 \\
3.75-7.92 \\
7.92-14.00\end{array}$ & $\begin{array}{l}125 \\
250 \\
700\end{array}$ & \begin{tabular}{|l|}
3300 \\
2900 \\
2450 \\
\end{tabular} & $\begin{array}{l}277 \\
389 \\
181\end{array}$ & $\begin{array}{l}277 \\
409 \\
205\end{array}$ & $\begin{array}{r}0 \\
2 \\
91\end{array}$ & $\begin{array}{r}00 \\
20 \\
1535\end{array}$ & $\begin{array}{l}0 \\
5.6 \\
6.9\end{array}$ & $\begin{array}{l}150 \\
10 \\
115\end{array}$ & $\begin{array}{r}+274 \\
+387 \\
+179\end{array}$ & $\begin{array}{r}+274 \\
+406 \\
+203\end{array}$ & $\begin{array}{r}0 \\
+\quad 9 \\
+\quad 91\end{array}$ & $\begin{array}{r}0 \\
+\quad 20 \\
+1535 \\
\end{array}$ & $\begin{array}{c}0 \\
+5.6 \\
+6.9\end{array}$ & $\begin{array}{r}+150 \\
+10 \\
+115\end{array}$ \\
\hline B. H. dit & $\begin{array}{l}\mathbf{A} \\
\mathbf{B} \\
\mathbf{C}\end{array}$ & $\begin{array}{r}0-10.75 \\
10.75-21.25 \\
21.25-26.75\end{array}$ & $\begin{array}{l}350 \\
440 \\
200\end{array}$ & $\begin{array}{l}7350 \\
3075 \\
2200\end{array}$ & $\begin{array}{r}1117 \\
190 \\
0\end{array}$ & $\begin{array}{r}1144 \\
283 \\
0\end{array}$ & $\begin{array}{r}2 \\
98 \\
45\end{array}$ & $\begin{array}{r}20 \\
767 \\
768\end{array}$ & & $\begin{array}{r}160 \\
198 \\
50\end{array}$ & $\begin{array}{r}+1107 \\
+170 \\
0\end{array}$ & $\begin{array}{r}+1129 \\
+260 \\
0\end{array}$ & $\begin{array}{r}0 \\
+\quad 95 \\
+45\end{array}$ & $\begin{array}{r}\overline{7} 6 \\
+768 \\
+768\end{array}$ & & $\begin{array}{l}+156 \\
+294 \\
+50\end{array}$ \\
\hline
\end{tabular}

Superscript (1), adjacent patient's initials, indicates one of different admissions.

- di $=$ died.

† Prt. = interval of urine collection before blood was drawn and treatment instituted.

$\mp$ Includes the electrolyte and nitrogen content of administered blood or albumin.

$\$ \mathrm{KCl}$ was administered orally in fruit juice and milk to M. C. (periods C and D), B. K. (period D) and A. F.1 (period $\mathrm{E}$ ). In periods $\mathrm{C}$ and $\mathrm{D}, \mathrm{A}, \mathrm{F}^{1}$ received $\mathrm{KCl}$ intravenously. $\mathrm{M}$. B. (period $\mathrm{C}$ ) and $\mathrm{B}$. $\mathrm{H}$. (periods $\mathrm{B}$ and $\mathrm{C}$ ) received intravenously a mixture of $\mathrm{K}_{2} \mathrm{HPO}_{4}$ and $\mathrm{KH}_{2} \mathrm{PO}_{4}$ of $\mathrm{pH} 7.4$ in saline and glucose. The composition of the oral intake of milk and fruit juice was estimated from tables (54).

II Balance data are expressed per individual period rather than cumulatively. The duration of a balance period is the interval between withdrawal of blood specimens, and may include several periods of urine collection which are listed separately in Table II. Balances of chloride and sodium are corrected for small quantities lost in blood drawn for analysis. 
TABLE II

Analytical data (blood, serum, and urine) of patients listed in Table I

\begin{tabular}{|c|c|c|c|c|c|c|c|c|c|c|c|c|c|c|c|c|c|c|c|}
\hline \multirow{3}{*}{$\begin{array}{c}\text { Pt. } \\
\text { Wt. } \\
\text { (kgm.) } \\
\underset{\text { S1.5 }}{\text { M. C. }}\end{array}$} & \multirow{2}{*}{ re- riod $^{*}$} & \multirow{2}{*}{ Duration } & \multicolumn{3}{|c|}{ Blood } & \multicolumn{7}{|c|}{ Serum } & \multicolumn{7}{|c|}{ Urine } \\
\hline & & & NPN & \multicolumn{2}{|c|}{ Glucose } & $\mathrm{HCO}_{2}$ & $\begin{array}{c}\text { Poten- } \\
\text { tial } \\
\mathrm{HCO}_{2} \ddagger\end{array}$ & $\mathrm{Cl}$ & $\mathrm{Na}$ & $\mathbf{K}$ & $\mathbf{P}$ & $\mathrm{H}_{2} \mathrm{O}$ & Flow & $\mathrm{Cl}$ & $\mathrm{Na}$ & $\mathbf{K}$ & $\mathbf{P}$ & $\mathbf{N}$ & Gluc. \\
\hline & $\begin{array}{l}\mathbf{A} \\
\mathbf{B} \\
\mathbf{C} \\
\mathbf{D}\end{array}$ & \begin{tabular}{|c|} 
hours \\
\\
$0-3.50$ \\
$3.50-7.50$ \\
$7.50-13.50$ \\
$13.50-17.50$ \\
$17.50-41.50$
\end{tabular} & $\begin{array}{c}m g . / \\
100 c c . \\
47 \\
43 \\
33 \\
27 \\
23\end{array}$ & \begin{tabular}{|c|}
$m g . /$ \\
$100 c c$. \\
528 \\
600 \\
270 \\
368
\end{tabular} & $\mid \begin{array}{c}\operatorname{lm} M . / \\
\text { liter } \\
29.3 \\
33.3 \\
15.0 \\
20.4\end{array}$ & $\begin{array}{r}\text { meq./ } \\
\text { liter } \\
\\
9.2 \\
14.0\end{array}$ & $\begin{array}{r}\text { meq./ } \\
\text { liter } \\
16.3 \\
7.0\end{array}$ & \begin{tabular}{|c|} 
meq. \\
liter \\
95.1 \\
97.3 \\
110.1 \\
102.2 \\
97.5
\end{tabular} & $\begin{array}{c}\text { meq./ } \\
\text { liter } \\
130.9 \\
127.8 \\
134.5 \\
128.2 \\
127.8\end{array}$ & \begin{tabular}{|c|} 
meq./ \\
liter \\
4.8 \\
4.3 \\
2.8 \\
3.4 \\
4.3
\end{tabular} & $\begin{array}{c}m g . / \\
100 c c . \\
4.51 \\
1.85 \\
0.40\end{array}$ & \begin{tabular}{|l|} 
gms. \\
liter \\
$878 \dagger$ \\
$910 \dagger$ \\
920 \\
920 \\
930
\end{tabular} & \begin{tabular}{|c|}
$c c . /$ \\
hour \\
\\
176 \\
270 \\
175 \\
275 \\
163
\end{tabular} & \begin{tabular}{|r|} 
meq./ \\
hour \\
\\
0.6 \\
6.3 \\
8.2 \\
11.8 \\
14.9
\end{tabular} & \begin{tabular}{|r|} 
meq./ \\
hour \\
\\
6.9 \\
6.8 \\
4.2 \\
4.8 \\
6.0
\end{tabular} & \begin{tabular}{|c|} 
meq./ \\
hour \\
\\
4.6 \\
3.8 \\
3.1 \\
3.5 \\
2.7 \\
\end{tabular} & \begin{tabular}{|c|} 
mg./ \\
hour \\
\\
100 \\
60 \\
25 \\
28
\end{tabular} & \begin{tabular}{|l|} 
gms./ \\
hour \\
0.40 \\
0.45 \\
0.52 \\
0.63 \\
0.41
\end{tabular} & \begin{tabular}{|r|} 
gms./ \\
hour \\
\\
6.7 \\
13.1 \\
8.5 \\
9.0 \\
3.0
\end{tabular} \\
\hline$\underset{61.5}{\text { B. K. }}$ & \begin{tabular}{|c|} 
Prt. \\
A \\
B \\
C \\
\end{tabular} & \begin{tabular}{|r|}
$0-0.87$ \\
$0.87-2.35$ \\
$2.35-5.62$ \\
$5.62-10.35$ \\
$10.35-22.35$ \\
\end{tabular} & $\begin{array}{l}42 \\
35 \\
27 \\
21 \\
26\end{array}$ & $\begin{array}{l}333 \\
249 \\
182 \\
232 \\
105\end{array}$ & $\begin{array}{r}18.5 \\
13.8 \\
10.1 \\
12.9 \\
5.8\end{array}$ & \begin{tabular}{l|}
10.6 \\
11.9 \\
15.9 \\
16.2 \\
20.0
\end{tabular} & \begin{tabular}{r|r|}
18.3 \\
18.8 \\
8.1 \\
8.3 \\
5.3
\end{tabular} & \begin{tabular}{|l|}
103.6 \\
103.2 \\
106.0 \\
108.2 \\
113.2 \\
\end{tabular} & \begin{tabular}{|l|}
137.5 \\
138.9 \\
135.0 \\
137.7 \\
143.5 \\
\end{tabular} & $\begin{array}{l}4.0 \\
3.5 \\
3.2 \\
2.8 \\
4.1\end{array}$ & $\begin{array}{r}2.80 \\
1.11 \\
\pm 0 \\
\pm 0\end{array}$ & \begin{tabular}{|l|}
$892 \dagger$ \\
$910 \dagger$ \\
$929+$ \\
930 \\
930 \\
\end{tabular} & $\begin{array}{r}125 \\
113 \\
86 \\
77 \\
55\end{array}$ & $\begin{array}{l}0.5 \\
0.7 \\
3.4 \\
2.5 \\
9.5\end{array}$ & $\begin{array}{l}7.7 \\
5.6 \\
1.8 \\
0.1 \\
2.1\end{array}$ & $\begin{array}{l}8.2 \\
4.7 \\
2.6 \\
1.2 \\
2.6\end{array}$ & $\begin{array}{r}68 \\
51 \\
24 \\
6\end{array}$ & \begin{tabular}{|l|}
0.57 \\
0.54 \\
0.55 \\
0.27 \\
0.29 \\
\end{tabular} & $\begin{array}{l}3.2 \\
3.3 \\
3.5 \\
0.4 \\
0.2\end{array}$ \\
\hline A. F.1 & $\begin{array}{c}\text { Prt. } \\
\text { A } \\
\text { B } \\
\text { C } \\
\text { D } \\
\text { E } \\
\end{array}$ & \begin{tabular}{|r|}
$0-0.62$ \\
$0.62-2.17$ \\
$2.17-2.74$ \\
$2.74-3.72$ \\
$3.72-4.89$ \\
$4.89-9.34$ \\
$9.34-33.34$ \\
$33.34-58.34$ \\
\end{tabular} & $\begin{array}{l}33 \\
32 \\
24 \\
23 \\
22 \\
28\end{array}$ & $\begin{array}{l}516 \\
472 \\
333 \\
396 \\
279 \\
404\end{array}$ & $\begin{array}{l}28.7 \\
26.2 \\
18.5 \\
22.0 \\
15.5 \\
22.5 \\
\end{array}$ & $\begin{array}{l}19.7 \\
22.4 \\
23.5\end{array}$ & $\begin{array}{r}1.7 \\
6.3 \\
11.1\end{array}$ & $\begin{array}{r}101.4 \\
106.7 \\
112.3 \\
110.0 \\
102.6 \\
94.7\end{array}$ & $\begin{array}{l}136.9 \\
134.8 \\
138.3 \\
136.4 \\
136.3 \\
134.3\end{array}$ & $\begin{array}{l}4.9 \\
4.2 \\
3.4 \\
3.4 \\
3.9 \\
4.0 \\
4.8\end{array}$ & $\begin{array}{l}4.11 \\
2.73\end{array}$ & $\begin{array}{l}904 \dagger \\
917 \dagger \\
930 \\
930 \\
930 \\
930\end{array}$ & $\begin{array}{l}292 \\
432 \\
186 \\
390 \\
166 \\
209 \\
142 \\
133\end{array}$ & \begin{tabular}{|r|}
7.8 \\
9.2 \\
7.6 \\
19.5 \\
13.5 \\
19.8 \\
12.4 \\
17.5 \\
\end{tabular} & \begin{tabular}{|r|}
19.4 \\
27.0 \\
14.2 \\
29.9 \\
13.5 \\
12.4 \\
6.5 \\
11.4 \\
\end{tabular} & $\begin{array}{l}8.2 \\
9.4 \\
3.4 \\
8.2 \\
8.9 \\
5.8 \\
4.2 \\
5.0\end{array}$ & $\begin{array}{r}90 \\
118 \\
29 \\
73 \\
21 \\
7 \\
5\end{array}$ & \begin{tabular}{|l|}
0.71 \\
0.77 \\
0.36 \\
0.75 \\
0.53 \\
0.53 \\
0.19 \\
0.24 \\
\end{tabular} & $\begin{array}{r}14.0 \\
19.2 \\
8.0 \\
16.8 \\
7.5 \\
10.7 \\
0.3 \\
0.6\end{array}$ \\
\hline $\begin{array}{l}\text { W.R. } \\
50.2\end{array}$ & \begin{tabular}{|c|} 
Prt. \\
A \\
B \\
C \\
D \\
\end{tabular} & $\begin{array}{r}0-1.48 \\
1.48-3.28 \\
3.28-5.60 \\
5.60-9.03 \\
9.03-21.03\end{array}$ & $\begin{array}{l}37 \\
33 \\
31 \\
34 \\
23\end{array}$ & $\begin{array}{r}333 \\
250 \\
255 \\
337 \\
40\end{array}$ & $\begin{array}{r}18.5 \\
13.9 \\
14.2 \\
18.7 \\
2.2\end{array}$ & \begin{tabular}{r|}
9.7 \\
16.4 \\
18.6 \\
18.3
\end{tabular} & \begin{tabular}{r|}
23.1 \\
10.4 \\
1.9 \\
5.9
\end{tabular} & \begin{tabular}{|l|}
101.4 \\
111.5 \\
109.6 \\
109.7 \\
113.3 \\
\end{tabular} & \begin{tabular}{|l|}
139.2 \\
139.7 \\
141.4 \\
135.2 \\
142.5 \\
\end{tabular} & $\begin{array}{l}4.6 \\
4.1 \\
3.3 \\
2.9 \\
2.7\end{array}$ & $\begin{array}{l}2.93 \\
1.31 \\
1.01 \\
0.67\end{array}$ & \begin{tabular}{|l|}
$898 \dagger$ \\
$906 \dagger$ \\
$920 \dagger$ \\
$927 \dagger$ \\
952 \\
\end{tabular} & \begin{tabular}{r|}
192 \\
164 \\
110 \\
112 \\
57
\end{tabular} & \begin{tabular}{|r|}
6.5 \\
6.6 \\
8.8 \\
10.6 \\
9.6 \\
\end{tabular} & \begin{tabular}{|r|}
12.3 \\
10.0 \\
3.9 \\
4.4 \\
5.1 \\
\end{tabular} & $\begin{array}{l}5.8 \\
4.2 \\
2.8 \\
2.3 \\
0.9\end{array}$ & $\begin{array}{r}95 \\
65 \\
28 \\
16 \\
9\end{array}$ & \begin{tabular}{|l|}
0.95 \\
0.89 \\
0.74 \\
0.62 \\
0.34 \\
\end{tabular} & $\begin{array}{l}9.3 \\
8.0 \\
7.5 \\
7.9 \\
0.2 \\
\end{array}$ \\
\hline $\mathbf{M}$ & \begin{tabular}{c|} 
Prt. \\
$\mathbf{A}$ \\
$\mathbf{B}$ \\
$\mathbf{C}$ \\
\end{tabular} & $\begin{array}{r}0-1.05 \\
1.05-3.55 \\
3.55-6.28 \\
6.28-11.25 \\
\end{array}$ & $\begin{array}{l}51 \\
46 \\
44 \\
40 \\
\end{array}$ & $\begin{array}{l}788 \\
659 \\
722 \\
642 \\
\end{array}$ & $\begin{array}{l}43.8 \\
36.6 \\
40.0 \\
35.7 \\
\end{array}$ & $\begin{array}{r}1.3 \\
5.3 \\
7.8 \\
14.8 \\
\end{array}$ & $\begin{array}{l}27.1 \\
23.6 \\
17.1 \\
12.0 \\
\end{array}$ & \begin{tabular}{r|}
94.3 \\
103.9 \\
110.9 \\
115.7 \\
\end{tabular} & $\begin{array}{l}127.7 \\
137.8 \\
140.8 \\
147.5 \\
\end{array}$ & $\begin{array}{l}4.8 \\
3.6 \\
3.2 \\
2.5 \\
\end{array}$ & $\begin{array}{l}7.95 \\
4.79 \\
1.41 \\
0.37 \\
\end{array}$ & $\begin{array}{l}879+ \\
887 \dagger \\
899 \dagger \\
907+ \\
\end{array}$ & \begin{tabular}{r|}
77 \\
300 \\
367 \\
260 \\
\end{tabular} & \begin{tabular}{|r|}
0.6 \\
7.2 \\
17.4 \\
13.0 \\
\end{tabular} & \begin{tabular}{r|}
1.0 \\
10.9 \\
17.4 \\
8.3 \\
\end{tabular} & $\begin{array}{l}1.0 \\
2.4 \\
2.2 \\
1.2 \\
\end{array}$ & $\begin{array}{r}41 \\
91 \\
34 \\
9 \\
\end{array}$ & $\begin{array}{l}0.15 \\
0.47 \\
0.53 \\
0.42 \\
\end{array}$ & $\begin{array}{r}3.5 \\
10.8 \\
10.6 \\
10.0 \\
\end{array}$ \\
\hline $.2 \mathrm{~N}$ & $\begin{array}{l}\mathbf{A} \\
\mathbf{B} \\
\mathbf{C}\end{array}$ & $\begin{array}{c}0-2.08 \\
2.08-5.08 \\
5.08-13.93\end{array}$ & $\begin{array}{l}53 \\
53 \\
44 \\
33 \\
\end{array}$ & $\begin{array}{r}690 \\
586 \\
280 \\
68\end{array}$ & $\begin{array}{r}38.3 \\
32.6 \\
15.5 \\
3.8\end{array}$ & \begin{tabular}{r|}
8.8 \\
9.3 \\
14.0
\end{tabular} & $\begin{array}{l}21.6 \\
23.2 \\
13.5\end{array}$ & \begin{tabular}{r|}
99.5 \\
103.7 \\
111.3 \\
110.5 \\
\end{tabular} & \begin{tabular}{|l|}
134.9 \\
141.2 \\
143.8 \\
144.4 \\
\end{tabular} & $\begin{array}{l}5.5 \\
4.7 \\
3.4 \\
3.8\end{array}$ & $\begin{array}{l}3.40 \\
2.13 \\
0.16 \\
0.82\end{array}$ & $\begin{array}{l}896 \dagger \\
899+ \\
910 \dagger \\
920 \dagger \\
\end{array}$ & $\begin{array}{r}218 \\
160 \\
48 \\
\end{array}$ & \begin{tabular}{|r|}
11.7 \\
11.3 \\
5.1 \\
\end{tabular} & \begin{tabular}{|r|}
14.4 \\
12.0 \\
3.1 \\
\end{tabular} & $\begin{array}{l}5.2 \\
4.1 \\
1.6\end{array}$ & $\begin{array}{r}27 \\
17 \\
6\end{array}$ & $\begin{array}{l}0.46 \\
0.53 \\
0.34 \\
\end{array}$ & $\begin{array}{l}6.9 \\
4.7 \\
0.9 \\
\end{array}$ \\
\hline A. P. & A & $0-12.00$ & $\begin{array}{l}38 \\
27\end{array}$ & $\begin{array}{l}720 \\
904\end{array}$ & $\begin{array}{l}40.0 \\
50.2\end{array}$ & $\begin{array}{r}8.5 \\
20.7\end{array}$ & $\begin{array}{r}23.2 \\
5.8\end{array}$ & $\begin{array}{r}96.2 \\
107.0\end{array}$ & $\begin{array}{l}132.9 \\
138.5\end{array}$ & $\begin{array}{l}3.5 \\
1.8\end{array}$ & & $\begin{array}{l}900 \\
925\end{array}$ & 278 & 18.4 & $|13.7|$ & 1.5 & & 0.45 & 4.0 \\
\hline H3. T. & $\stackrel{\text { A }}{\text { B }}$ & $\begin{array}{r}0-1.83 \\
1.83-5.47\end{array}$ & $\begin{array}{l}45 \\
49 \\
43\end{array}$ & $\begin{array}{l}968 \\
994 \\
800 \\
\end{array}$ & $\begin{array}{l}53.8 \\
55.3 \\
44.4 \\
\end{array}$ & 6.2 & 25.7 & $\begin{array}{r}97.9 \\
102.6 \\
110.3 \\
\end{array}$ & \begin{tabular}{|l|}
134.8 \\
135.3 \\
139.7 \\
\end{tabular} & $\begin{array}{l}5.5 \\
4.8 \\
2.9\end{array}$ & \begin{tabular}{l|}
6.20 \\
5.43 \\
1.32 \\
\end{tabular} & $\begin{array}{l}900 \\
910 \\
920 \\
\end{array}$ & $\begin{array}{l}41 \\
67 \\
\end{array}$ & $\begin{array}{l}1.1 \\
5.0 \\
\end{array}$ & $\begin{array}{l}1.6 \\
4.1 \\
\end{array}$ & $\begin{array}{l}0.5 \\
0.6\end{array}$ & $\begin{array}{l}6 \\
4 \\
\end{array}$ & $\begin{array}{l}0.05 \\
0.08 \\
\end{array}$ & $\begin{array}{l}1.0 \\
1.6 \\
\end{array}$ \\
\hline $\begin{array}{l}\text { M. B. } \\
41.0\end{array}$ & $\begin{array}{l}\mathbf{A} \\
\mathbf{B} \\
\mathbf{C}\end{array}$ & $\begin{array}{c}0-3.75 \\
3.75-7.92 \\
7.92-14.00\end{array}$ & $\begin{array}{l}68 \\
55\end{array}$ & $\begin{array}{l}1676 \\
1480 \\
1800\end{array}$ & $\begin{array}{r}93.2 \\
82.2 \\
100.0 \\
\end{array}$ & $\begin{array}{r}4.8 \\
11.5\end{array}$ & $\begin{array}{r}18.7 \\
8.8\end{array}$ & $\begin{array}{l}76.5 \\
91.6 \\
71.1\end{array}$ & \begin{tabular}{r|}
105.0 \\
116.9 \\
87.5 \\
\end{tabular} & $\begin{array}{l}4.3 \\
3.5 \\
5.8\end{array}$ & $\begin{array}{l}4.25 \\
2.00 \\
6.04\end{array}$ & \begin{tabular}{|l|}
900 \\
910 \\
920
\end{tabular} & $\begin{array}{l}\mathbf{0} \\
\mathbf{0} \\
\mathbf{0}\end{array}$ & & & & & & \\
\hline $\begin{array}{l}\text { B. } \mathrm{H} . \\
50.0\end{array}$ & $\begin{array}{l}\mathbf{A} \\
\mathbf{B} \\
\mathbf{C}\end{array}$ & $\left|\begin{array}{r}0-10.75 \\
10.75-21.25 \\
21.25-26.75\end{array}\right|$ & 70 & $\begin{array}{l}1300 \\
1211 \\
1160 \\
1130\end{array}$ & $\begin{array}{l}72.2 \\
67.3 \\
64.5 \\
62.8\end{array}$ & $\begin{array}{r}4.4 \\
8.4 \\
13.3\end{array}$ & $\begin{array}{l}30.0 \\
15.3 \\
12.7\end{array}$ & $\begin{array}{r}71.0 \\
100.9 \\
99.5 \\
100.3\end{array}$ & $\begin{array}{l}110.4 \\
129.6 \\
130.5 \\
135.0\end{array}$ & $\begin{array}{l}5.6 \\
2.8 \\
2.9 \\
3.4\end{array}$ & $\begin{array}{r}10.10 \\
2.56 \\
2.47 \\
4.15\end{array}$ & $\begin{array}{l}890 \\
905 \\
915 \\
920\end{array}$ & $\begin{array}{r}13 \\
25 \\
0\end{array}$ & $\begin{array}{l}0.3 \\
1.1\end{array}$ & $\begin{array}{l}0.4 \\
1.1\end{array}$ & $\begin{array}{l}0.2 \\
0.2\end{array}$ & $\begin{array}{l}2 \\
1\end{array}$ & & $\begin{array}{l}0.3 \\
0.7\end{array}$ \\
\hline
\end{tabular}

* Blood was drawn at the end of corresponding urine-collection periods.

$\dagger=$ directly determined by the difference between wet and dry weights. The other values for serum water were either calculated from the concentration of total protein or assumed.

$\ddagger$ Potential $\mathrm{HCO}_{3}=[\mathrm{Na}]-\left([\mathrm{Cl}]+\left[\mathrm{HCO}_{3}\right]+5\right)$.

Darrow (23). Changes in extracellular volume were calculated from alterations in the chloride space forward or backward from an assumed extracellular volume. Cellular transfers of potassium and phosphorus were not corrected for the balance of cellular nitrogen because the brevity of the balance periods introduced too great an error. In four instances where the concentration of serum chloride was not determined (Table IV, M.Be, M.Br ${ }^{1}$, M.Br ${ }^{2}, A . F^{2}$ ), alterations in extracellular volume were estimated from the external balance of chloride. The values obtained were used only for the estimations of cellular transfers of glucose, a calculation which is not significantly influenced by the error thus introduced.
Two assumptions were made in calculating the exchanges of glucose: 1) free glucose is essentially extracellular in location; 2) the average concentration of glucose in the extracellular fluid is equal to its concentration in blood. Pareira and Somogyi (24) have assumed that the concentration of glucose in the extracellular fluid is 20 per cent lower than the blood sugar because the removal of glucose by cells creates steep gradients; but since the presence and magnitude of such gradients are unknown in diabetic acidosis, and since the correction of the concentration of glucose in whole blood for red cell solids would at least partially cancel them, the concentration of glucose in whole blood was taken to be the average concentration within its volume of distribution. 
RESULTS

Analytical and derived data are presented in Tables I-IV and Figures 1 and 2.

Clinical and chemical findings on admission. Five patients (E.M., M.N., H.T., M.B., and
B.H.) manifested clinical evidences of profound salt depletion and dehydration, peripheral vascular collapse and deep coma. These clinical features rather than any chemical findings constituted the best index of the severity of the disorder (25).

TABLE III

Extracellular and intracellular balances of patients listed in Table I

\begin{tabular}{|c|c|c|c|c|c|c|c|c|c|c|c|c|c|}
\hline \multirow{3}{*}{$\begin{array}{l}\text { Patient } \\
\text { M. C. }\end{array}$} & \multirow{3}{*}{$\begin{array}{c}\text { Period } \\
\\
\text { A } \\
\text { B } \\
\text { C } \\
\text { D }\end{array}$} & \multirow{3}{*}{$\begin{array}{c}\begin{array}{c}\text { Extra-* } \\
\text { cellular } \\
\text { volume }\end{array} \\
\\
\text { liters } \\
8.1 \\
11.2 \\
10.6 \\
12.9 \\
(11.9)\end{array}$} & \multicolumn{4}{|c|}{ Extracellular balance } & \multicolumn{7}{|c|}{ Intracellular balance } \\
\hline & & & \multirow[b]{2}{*}{\begin{tabular}{|c|}
$\mathrm{Na}$ \\
meq. \\
+342 \\
$\begin{array}{r}20 \\
+\end{array} 236$ \\
-158
\end{tabular}} & \multirow[b]{2}{*}{$\begin{array}{c}\mathrm{K} \\
\text { meq. } \\
+9 \\
+18 \\
+14 \\
+7\end{array}$} & \multirow{2}{*}{$\begin{array}{c}P \\
m g . \\
-154 \\
-155\end{array}$} & \multirow{2}{*}{$\begin{array}{c}\text { Glucose } \\
\text { gms. } \\
+24 \\
+38 \\
+18\end{array}$} & \multirow[b]{2}{*}{$\begin{array}{c}\mathrm{Na} \\
\text { meq. } \\
-30 \\
+116 \\
\overline{+} 62 \\
+56\end{array}$} & \multicolumn{2}{|c|}{$\mathrm{K} t$} & \multicolumn{2}{|c|}{ P† } & \multicolumn{2}{|c|}{ Glucose } \\
\hline & & & & & & & & $\begin{array}{l}\text { meq. } \\
-36 \\
+\quad 1 \\
+22 \\
+112\end{array}$ & $\begin{array}{l}\begin{array}{c}\text { meq.I } \\
\text { hour }\end{array} \\
\\
-4.8 \\
+0.2 \\
+5.5 \\
+4.7\end{array}$ & $\begin{array}{r}\text { meg. } \\
-336 \\
+161 \ddagger\end{array}$ & $\begin{array}{c}\text { meq./ } \\
\text { hour } \\
-45 \\
+16 \ddagger\end{array}$ & $\begin{array}{l}\text { gms. } \\
+100 \\
+84 \\
+122\end{array}$ & $\begin{array}{l}\text { gms./ } \\
\text { hour } \\
\\
+13 \\
+17 \\
+31\end{array}$ \\
\hline B. $\mathrm{K}$. & $\begin{array}{l}\text { Prt. } \\
\text { A } \\
\text { B } \\
\text { C } \\
\text { D }\end{array}$ & $\begin{array}{c}8.5 \\
10.1 \\
12.0 \\
12.7 \\
(12.3)\end{array}$ & $\begin{array}{r}+220 \\
+\quad 194 \\
+\quad 125 \\
+\quad 21\end{array}$ & $\begin{array}{l}+1 \\
+3 \\
+2 \\
+14\end{array}$ & $\begin{array}{r}-126 \\
-112 \\
0\end{array}$ & $\begin{array}{l}-\quad 3 \\
-\quad 3 \\
+\quad 7 \\
-\quad 16\end{array}$ & $\begin{array}{r}79 \\
+\quad 45 \\
+\quad 7 \\
-\quad 27\end{array}$ & $\begin{array}{l}-\quad 9 \\
-12 \\
=4 \\
+103\end{array}$ & $\begin{array}{l}-6.1 \\
-3.7 \\
-0.8 \\
+8.6\end{array}$ & $\begin{array}{l}+51 \\
+35 \\
-30\end{array}$ & $\begin{array}{l}+34 \\
+\quad 11 \\
-\quad 6\end{array}$ & $\begin{array}{l}+26 \\
+51 \\
+141 \\
+114\end{array}$ & $\begin{array}{l}+18 \\
+16 \\
+30 \\
+10\end{array}$ \\
\hline A. F. & $\begin{array}{c}\text { Prt. } \\
\text { A } \\
\text { B } \\
\text { C } \\
\text { D } \\
\text { E }\end{array}$ & $\begin{array}{r}(7.3) \\
8.3 \\
9.2 \\
10.1 \\
10.3 \\
8.6\end{array}$ & $\begin{array}{r}+108 \\
+\quad 142 \\
+\quad 108 \\
+\quad 27 \\
+\quad 255\end{array}$ & $\begin{array}{r}-1 \\
-4 \\
+8 \\
+2 \\
0\end{array}$ & -74 & $\begin{array}{lr}+ & 1 \\
& 8 \\
+ & 9 \\
& 11 \\
+ & 6\end{array}$ & $\begin{array}{l}+12 \\
-\quad 2 \\
-66 \\
-55 \\
-\quad 11\end{array}$ & $\begin{array}{l}-14 \\
-10 \\
+44 \\
+\quad 7 \\
+106\end{array}$ & $\begin{array}{l}-9.0 \\
-3.7 \\
+9.9 \\
+0.3 \\
+4.2\end{array}$ & -110 & -71 & $\begin{array}{r}+7 \\
+19 \\
+110 \\
+320 \\
+241\end{array}$ & $\begin{array}{l}+5 \\
+7 \\
+25 \\
+13 \\
+10\end{array}$ \\
\hline W. R. & $\begin{array}{l}\text { Prt. } \\
\text { A } \\
\text { B } \\
\text { C } \\
\text { D }\end{array}$ & $\begin{array}{r}(7.5) \\
8.1 \\
9.2 \\
9.7 \\
11.1\end{array}$ & $\begin{array}{rr}+ & 77 \\
+ & 158 \\
+ & 5 \\
+ & 236\end{array}$ & $\begin{array}{l}-2 \\
-3 \\
-2 \\
+2\end{array}$ & $\begin{array}{l}-114 \\
-\quad 6 \\
-\quad 35\end{array}$ & $\begin{array}{r}5 \\
+\quad 4 \\
+\quad 9 \\
-\quad 28\end{array}$ & $\begin{array}{l}+62 \\
+40 \\
+68 \\
+\quad 6\end{array}$ & $\begin{array}{l}-\quad 5 \\
-\quad 3 \\
=\quad 6 \\
=\quad 13\end{array}$ & $\begin{array}{l}-2.8 \\
-1.4 \\
-1.7 \\
-1.1\end{array}$ & $\begin{array}{l}-2 \\
-53 \\
-15\end{array}$ & $\begin{array}{l}-\quad 1 \\
-\quad 24 \\
-\quad 4\end{array}$ & $\begin{array}{l}+11 \\
+20 \\
+60 \\
+138\end{array}$ & $\begin{array}{l}+6 \\
+9 \\
+18 \\
+12\end{array}$ \\
\hline E. M. & $\begin{array}{l}\text { Prt. } \\
\text { A } \\
\text { B } \\
\text { C }\end{array}$ & $\begin{array}{l}5.4 \\
7.0 \\
7.1 \\
(7.3)\end{array}$ & $\begin{array}{r}+287 \\
+\quad 23 \\
+\quad 73\end{array}$ & $\begin{array}{l}-1 \\
-2 \\
-5\end{array}$ & $\begin{array}{r}-93 \\
-236 \\
-\quad 73\end{array}$ & $\begin{array}{r}+3 \\
+\quad 5 \\
-\quad 4\end{array}$ & $\begin{array}{l}-37 \\
+33 \\
+\quad 17\end{array}$ & $\begin{array}{r}-4 \\
-\quad 4 \\
0\end{array}$ & $\begin{array}{c}-1.6 \\
-1.5 \\
0\end{array}$ & $\begin{array}{l}-128 \\
+147 \\
+36\end{array}$ & $\begin{array}{l}-51 \\
+54 \\
+\quad 7\end{array}$ & $\begin{array}{l}-10 \\
+16 \\
+53\end{array}$ & $\begin{array}{l}-4 \\
+6 \\
+11\end{array}$ \\
\hline & $\begin{array}{l}\mathbf{A} \\
\mathbf{B} \\
\mathbf{C}\end{array}$ & $\begin{array}{c}(5.8) \\
6.7 \\
7.5 \\
8.2\end{array}$ & $\begin{array}{r}+171 \\
+\quad 125 \\
+\quad 98\end{array}$ & $\begin{array}{l}-1 \\
-6 \\
+6\end{array}$ & $\begin{array}{r}-54 \\
-131 \\
+55\end{array}$ & $\begin{array}{r}+13 \\
+\quad 5 \\
-\quad 4\end{array}$ & $\begin{array}{r}-34 \\
+41 \\
-11\end{array}$ & $\begin{array}{l}-8 \\
-\quad 5 \\
-21\end{array}$ & $\begin{array}{l}-3.8 \\
-1.7 \\
-2.4\end{array}$ & $\begin{array}{l}+\quad 7 \\
+\quad 91 \\
-\quad 2\end{array}$ & $\begin{array}{cc}+ & 3 \\
+ & 30 \\
- & 0.2\end{array}$ & $\begin{array}{l}+7 \\
+34 \\
+150\end{array}$ & $\begin{array}{l}+3 \\
+11 \\
+17\end{array}$ \\
\hline. $\mathrm{r}$ & A & $\left(\begin{array}{c}5.5) \\
10.2\end{array}\right.$ & +680 & -1 & & +52 & -1 & -17 & -1.4 & & & +202 & +17 \\
\hline 1. 1. & $\begin{array}{l}\mathbf{A} \\
\mathbf{B}\end{array}$ & $\begin{array}{r}(6.4) \\
8.3 \\
11.0\end{array}$ & $\begin{array}{r}+262 \\
+416\end{array}$ & $\begin{array}{l}+5 \\
-8\end{array}$ & $\begin{array}{l}+34 \\
-309\end{array}$ & $\begin{array}{l}+21 \\
+\quad 5\end{array}$ & $\begin{array}{l}-\quad 4 \\
-\quad 4\end{array}$ & $\begin{array}{r}-5 \\
+\quad 7\end{array}$ & $\begin{array}{l}-2.7 \\
+1.9\end{array}$ & $\begin{array}{r}39 \\
+309\end{array}$ & $\begin{array}{l}-21 \\
+85\end{array}$ & $\begin{array}{l}-23 \\
+69\end{array}$ & $\begin{array}{l}-13 \\
+19\end{array}$ \\
\hline M. B. & $\begin{array}{l}\mathbf{A} \\
\mathbf{B} \\
\mathbf{C}\end{array}$ & 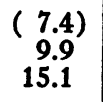 & $\begin{array}{l}+389 \\
+155\end{array}$ & $\begin{array}{r}+3 \\
+53\end{array}$ & $\begin{array}{l}+117 \\
+716\end{array}$ & $\begin{array}{l}+23 \\
+125\end{array}$ & $\begin{array}{l}+17 \\
+48\end{array}$ & $\begin{array}{l}1 \\
+38\end{array}$ & $\begin{array}{l}-0.2 \\
+6.2\end{array}$ & $\begin{array}{r}+97 \\
+819\end{array}$ & $\begin{array}{r}23 \\
+135\end{array}$ & $\begin{array}{l}-13 \\
-10\end{array}$ & $\begin{array}{l}-3 \\
-2\end{array}$ \\
\hline B. $\mathrm{H}$. & $\begin{array}{l}\mathbf{A} \\
\mathbf{B} \\
\mathbf{C}\end{array}$ & $\begin{array}{c}(7.5) \\
14.8 \\
16.6 \\
16.5\end{array}$ & $\begin{array}{r}+1120 \\
+\quad 246 \\
+\quad 47\end{array}$ & $\begin{array}{l}-1 \\
+7 \\
+8\end{array}$ & $\begin{array}{r}-379 \\
+\quad 31 \\
+275\end{array}$ & $\begin{array}{l}+81 \\
+14 \\
-\quad 6\end{array}$ & $\begin{array}{l}+9 \\
+14 \\
-47\end{array}$ & $\begin{array}{l}+1 \\
+\quad 88 \\
+37\end{array}$ & $\begin{array}{l}+0.1 \\
+8.4 \\
+6.3\end{array}$ & $\begin{array}{l}+373 \\
+737 \\
+493\end{array}$ & $\begin{array}{l}+35 \\
+70 \\
+85\end{array}$ & $\begin{array}{l}+75 \\
+280 \\
+56\end{array}$ & $\begin{array}{l}+7 \\
+27 \\
+10\end{array}$ \\
\hline
\end{tabular}

* Calculated by changes in chloride balance, forward or backward, from an assumed extracellular volume (designated by parentheses).

$t$ Intracellular exchanges of $K$ and $P$ are not corrected for nitrogen.

I Includes periods $B$ and $C$. 
Blood transfusions at the onset of treatment seemed largely responsible for the dramatic response of E.M. and M.N.; while the failure of repeated transfusions and other measures to alter the fatal course of the other three patients indicate the presence of irreversible shock. The chemical findings in the blood and urine of these patients in vascular collapse are included in Table II. It is noteworthy that, although three of these patients were either markedly oliguric (H.T. and B.H.) or anuric (M.B.), the urine flow of E.M. before treatment and despite the presence of vascular collapse was moderately accelerated (77 cc./ hour). Neither the N.P.N. nor the concentrations of serum sodium and chloride reflected the severity of the disease or the magnitude of the salt depletion, save in a general way. Although the N.P.N. tended to be higher in patients in shock, ranging from 45 to $70 \mathrm{mg}$. per cent, these values are not exceptionally elevated for diabetic acidosis, and the highest N.P.N. in the study was in a patient without evidence of collapse (Table IV, M.Be). The concentration of serum sodium (Table II) was extremely low (105 to 110 meq.) liter) in two cases in shock (M.B. and B.H.), but was normal in H.T. and M.N., and only moderately depressed in E.M., despite apparently comparable salt depletion.

The initial concentrations of serum electrolytes for ten patients (including those in collapse on admission) are listed in Table II. The bicarbonate, which suffered on the whole the greatest absolute reduction, varied from 1.3 to 10.6 meq./ liter, the average being 7.2. This depression of the bicarbonate, however, does not represent sodium bicarbonate lost from the body, but is rather principally a consequence of the accession of fixed acids to the blood which displace bicarbonate from combination with sodium, a process which can be completely reversed without the addition of exogenous sodium salts by restoration of the ability to burn carbohydrate. Hence the difference,

TABLE IV

The effect of massive injections of glucose on water and electrolyte excretion and carbohydrate balances during treatment of diabetic acidosis

\begin{tabular}{|c|c|c|c|c|c|c|c|c|c|c|c|c|c|c|c|c|c|c|c|}
\hline \multirow{2}{*}{$\begin{array}{c}\text { Patient } \\
\text { (age-gex) } \\
\text { Wt. (kgm.) }\end{array}$} & \multirow{2}{*}{$\begin{array}{l}\text { Pe- } \\
\text { riod }\end{array}$} & \multirow{2}{*}{ Duration } & \multicolumn{5}{|c|}{ Intake } & \multicolumn{6}{|c|}{ Urine } & \multicolumn{2}{|c|}{ Blood*t } & \multicolumn{4}{|c|}{ Glucose balance } \\
\hline & & & $\begin{array}{c}\text { Insu- } \\
\text { lin }\end{array}$ & $\mathrm{H}_{2} \mathrm{O}$ & Cl & $\mathrm{Na}$ & Gluc. & Flow & $\mathrm{Cl}$ & $\mathbf{N a}$ & $\mathbf{K}$ & $\mathbf{N}$ & Gluc. & NPN & Gluc. & $\underset{\text { ternal }}{\text { Ex- }}$ & $\begin{array}{l}\text { Extra- } \\
\text { cellu- }\end{array}$ & Intrac & ellular \\
\hline $\begin{array}{c}\text { M. Be } \\
(60 \%) \\
60.5\end{array}$ & $\begin{array}{l}\mathbf{A} \\
\mathbf{B} \\
\mathbf{C}\end{array}$ & $\begin{array}{c}\text { hours } \\
0-2.50 \\
2.50-3.75 \\
3.75-6.83\end{array}$ & $\begin{array}{r}\text { urits } \\
100 \\
80 \\
70\end{array}$ & $\begin{array}{r}c c . \\
2950 \\
750 \\
2600\end{array}$ & $\begin{array}{l}\text { meq. } \\
347 \\
116 \\
231\end{array}$ & $\begin{array}{l}\text { meq. } \\
\\
347 \\
116 \\
231\end{array}$ & $\begin{array}{r}\text { ems. } \\
150 \\
0 \\
125\end{array}$ & $\begin{array}{l}\text { cc./ } \\
\text { hour } \\
\\
268 \\
466 \\
169\end{array}$ & \begin{tabular}{|c|} 
meq./ \\
hour \\
\\
3.8 \\
8.4 \\
6.1
\end{tabular} & meq./ & \begin{tabular}{|c|} 
meq./ \\
hour \\
4.0 \\
4.1 \\
1.1
\end{tabular} & $\begin{array}{l}\text { grms./ } \\
\text { hour } \\
\\
0.80 \\
1.33 \\
0.34\end{array}$ & $\begin{array}{r}\text { gms./ } \\
\text { hour } \\
\\
14.9 \\
25.8 \\
7.4\end{array}$ & $\begin{array}{c}\text { mg./ } \\
100 \text { cc. } \\
76 \\
53 \\
51 \\
52\end{array}$ & \begin{tabular}{|c|} 
mg./ \\
100 cc. \\
532 \\
922 \\
842 \\
1036
\end{tabular} & $\begin{array}{l}\text { gms. } \\
+113 \\
+32 \\
+102\end{array}$ & $\begin{array}{l}\text { gms. } \\
+57 \\
+38 \\
\end{array}$ & $\begin{array}{l}\text { ems. } \\
+56 \\
-28 \\
+64\end{array}$ & $\begin{array}{l}\text { grms./ } \\
\text { hour } \\
+22 \\
+22 \\
+21\end{array}$ \\
\hline $\begin{array}{c}\text { M. } \mathrm{Br}^{1} \\
(22 \text { 8) } \\
54.6\end{array}$ & $\begin{array}{l}\mathbf{A} \\
\mathbf{B} \\
\mathbf{C}\end{array}$ & $\begin{array}{r}0-2.33 \\
2.33-4.58 \\
4.58-7.41\end{array}$ & $\begin{array}{r}140 \\
70 \\
20 \\
\end{array}$ & $\begin{array}{l}1825 \\
1800 \\
2375 \\
\end{array}$ & $\begin{array}{l}154 \\
185 \\
231 \\
\end{array}$ & $\begin{array}{l}154 \\
185 \\
231 \\
\end{array}$ & $\begin{array}{l}145 \\
100 \\
145 \\
\end{array}$ & $\begin{array}{l}750 \\
489 \\
335\end{array}$ & $\begin{array}{r}21.4 \\
7.7 \\
8.1\end{array}$ & & $\begin{array}{l}8.7 \\
2.6 \\
3.6\end{array}$ & $\begin{array}{l}0.59 \\
0.52 \\
0.41\end{array}$ & $\begin{array}{l}51.2 \\
42.9 \\
30.8 \\
\end{array}$ & & $\begin{array}{l}780 \\
860 \\
800 \\
468\end{array}$ & $\begin{array}{r}27 \\
+\quad 4 \\
+58\end{array}$ & $\begin{array}{r}+13 \\
+3 \\
-24\end{array}$ & & $\begin{array}{l}+6 \\
+1 \\
+29\end{array}$ \\
\hline $\begin{array}{c}\text { M. } \mathrm{Br}^{2} \\
(22 \&)\end{array}$ & $\begin{array}{l}\mathbf{A} \\
\mathbf{B}\end{array}$ & $\begin{array}{r}0-3.00 \\
3.00-6.25\end{array}$ & $\begin{array}{r}140 \\
70\end{array}$ & $\begin{array}{l}3400 \\
1350\end{array}$ & $\begin{array}{l}416 \\
116\end{array}$ & $\begin{array}{l}416 \\
116\end{array}$ & $\begin{array}{l}150 \\
100\end{array}$ & $\begin{array}{l}312 \\
211\end{array}$ & $\begin{array}{l}6.4 \\
3.6\end{array}$ & & $\begin{array}{l}4.6 \\
3.3\end{array}$ & $\begin{array}{l}0.31 \\
0.33\end{array}$ & $\begin{array}{l}17.0 \\
14.2\end{array}$ & $\begin{array}{l}32 \\
29 \\
27\end{array}$ & $\begin{array}{l}582 \\
552 \\
372\end{array}$ & $\begin{array}{l}+99 \\
+54\end{array}$ & $\begin{array}{l}+12 \\
-17\end{array}$ & $\begin{array}{l}+87 \\
+71\end{array}$ & $\begin{array}{l}+29 \\
+22\end{array}$ \\
\hline $\begin{array}{c}\text { A. F.2 } \\
(24 \%) \\
45.6\end{array}$ & $\begin{array}{c}\text { Prt. } \\
\mathbf{A} \\
\mathbf{B}\end{array}$ & $\begin{array}{r}0-1.00 \\
1.00-4.92 \\
4.92-8.42\end{array}$ & $\begin{array}{r}0 \\
150 \\
40\end{array}$ & $\begin{array}{r}0 \\
2200 \\
1800\end{array}$ & $\begin{array}{r}0 \\
231 \\
185\end{array}$ & $\begin{array}{r}0 \\
231 \\
185\end{array}$ & $\begin{array}{r}0 \\
150 \\
100\end{array}$ & $\begin{array}{r}90 \\
421 \\
184\end{array}$ & $\begin{array}{c}0 \\
10.1 \\
3.8\end{array}$ & & $\begin{array}{l}5.0 \\
3.6\end{array}$ & $\begin{array}{l}0.26 \\
0.59 \\
0.38\end{array}$ & $\begin{array}{r}4.3 \\
24.3 \\
14.9\end{array}$ & $\begin{array}{l}28 \\
29 \\
26\end{array}$ & $\begin{array}{l}453 \\
469 \\
286\end{array}$ & $\begin{array}{l}+55 \\
+48\end{array}$ & $\begin{array}{l}+6 \\
-11\end{array}$ & & $\begin{array}{l}+13 \\
+17\end{array}$ \\
\hline O. W. & $\begin{array}{c}\text { Prt. } \\
\text { A } \\
\text { B }\end{array}$ & $\begin{array}{r}0-0.50 \\
0.50-3.50 \\
3.50-6.50\end{array}$ & $\begin{array}{r}0 \\
180 \\
100\end{array}$ & $\begin{array}{r}2200 \\
3600\end{array}$ & $\begin{array}{r}0 \\
231 \\
370\end{array}$ & $\begin{array}{r}0 \\
231 \\
370\end{array}$ & $\begin{array}{r}0 \\
150 \\
100\end{array}$ & $\begin{array}{l}232 \\
700 \\
503\end{array}$ & \begin{tabular}{r|}
6.8 \\
31.4 \\
21.3
\end{tabular} & & \begin{tabular}{r|}
10.7 \\
9.5 \\
8.7
\end{tabular} & $\begin{array}{l}0.38 \\
0.68 \\
0.58\end{array}$ & $\begin{array}{l}11.1 \\
33.8 \\
30.0\end{array}$ & $\begin{array}{l}34 \\
33 \\
31\end{array}$ & $\begin{array}{l}388 \\
649 \\
400\end{array}$ & $\begin{array}{l}+48 \\
+10\end{array}$ & $\begin{array}{l}+29 \\
-16\end{array}$ & $\begin{array}{l}+19 \\
+26\end{array}$ & $\begin{array}{l}+6 \\
+9\end{array}$ \\
\hline$\underset{(58 \%)}{\text { M. }}$ & $\begin{array}{c}\text { Prt. } \\
\text { A } \\
\text { B }\end{array}$ & $\begin{array}{r}0-0.75 \\
0.75-4.00 \\
4.00-7.00\end{array}$ & $\begin{array}{r}0 \\
140 \\
100\end{array}$ & $\begin{array}{r}290 \\
2950 \\
1350\end{array}$ & $\begin{array}{r}0 \\
347 \\
116\end{array}$ & $\begin{array}{r}0 \\
347 \\
116\end{array}$ & $\begin{array}{r}0 \\
150 \\
100\end{array}$ & $\begin{array}{l}217 \\
286 \\
376\end{array}$ & $\begin{array}{l}1.9 \\
5.0 \\
7.1\end{array}$ & \begin{tabular}{r|}
7.2 \\
10.5 \\
10.6
\end{tabular} & $\begin{array}{l}6.9 \\
4.9 \\
3.5\end{array}$ & $\begin{array}{l}0.46 \\
0.57 \\
0.62\end{array}$ & $\begin{array}{r}9.5 \\
21.5 \\
24.1\end{array}$ & $\begin{array}{l}48 \\
43 \\
35\end{array}$ & $\begin{array}{l}688 \\
840 \\
628\end{array}$ & $\begin{array}{l}+80 \\
+28\end{array}$ & $\begin{array}{l}+32 \\
-27\end{array}$ & $\begin{array}{l}+48 \\
+55\end{array}$ & $\begin{array}{l}+1 \\
+1\end{array}$ \\
\hline R. R. & $\begin{array}{l}\text { Prt. } \\
\text { A } \\
\text { B } \\
\text { C } \\
\text { D } \\
\mathbf{E} \\
\text { F }\end{array}$ & $\begin{array}{r}0-0.83 \\
0.83-2.83 \\
2.83-4.41 \\
4.41-5.74 \\
5.74-7.74 \\
7.74-9.91 \\
9.91-12.49\end{array}$ & $\begin{array}{r}0 \\
100 \\
70 \\
30 \\
20 \\
50 \\
40\end{array}$ & $\begin{array}{r}0 \\
1375 \\
1900 \\
1475 \\
725 \\
550 \\
1725\end{array}$ & \begin{tabular}{r|}
0 \\
293 \\
200 \\
123 \\
77 \\
0 \\
200
\end{tabular} & $\begin{array}{r}0 \\
293 \\
200 \\
123 \\
77 \\
0 \\
200\end{array}$ & $\begin{array}{r}0 \\
204 \\
83 \\
63 \\
38 \\
92 \\
71\end{array}$ & $\begin{array}{l}251 \\
720 \\
372 \\
289 \\
473 \\
256 \\
104\end{array}$ & \begin{tabular}{r|}
2.9 \\
19.5 \\
12.3 \\
8.9 \\
16.6 \\
10.7 \\
5.3
\end{tabular} & \begin{tabular}{r|}
13.4 \\
28.7 \\
14.1 \\
7.7 \\
10.1 \\
3.7 \\
0.98
\end{tabular} & \begin{tabular}{r|}
12.4 \\
10.8 \\
5.0 \\
4.1 \\
3.7 \\
2.4 \\
1.0
\end{tabular} & $\begin{array}{l}0.73 \\
0.86 \\
0.40 \\
0.35 \\
0.57 \\
0.49 \\
0.24\end{array}$ & \begin{tabular}{r|}
12.1 \\
43.4 \\
25.3 \\
22.6 \\
37.8 \\
24.0 \\
9.8
\end{tabular} & $\begin{array}{l}35 \\
33 \\
28 \\
26 \\
23 \\
19\end{array}$ & $\begin{array}{l}484 \\
988 \\
824 \\
728 \\
576 \\
476 \\
338\end{array}$ & $\begin{array}{l}+117 \\
+43 \\
+33 \\
+38 \\
+40 \\
+46\end{array}$ & $\begin{array}{r}+53 \\
-4 \\
-8 \\
-13 \\
-12 \\
-8\end{array}$ & $\begin{array}{l}+64 \\
+47 \\
+41 \\
-25 \\
+52 \\
+54\end{array}$ & $\begin{array}{l}+32 \\
+30 \\
+31 \\
+13 \\
+24 \\
+21\end{array}$ \\
\hline
\end{tabular}

Superscripts (1) or (2), adjacent patients' initials, indicate different admissions.

- Blood was drawn at the end of corresponding urine collection periods.

+ Determinations of the concentrations of $\mathrm{CO}_{2}$ and $\mathrm{Cl}$ were obtained initially in all cases; values for $\mathrm{CO}_{2}$ ranged from 4.9 to $12.2 \mathrm{meq}$./liter. 


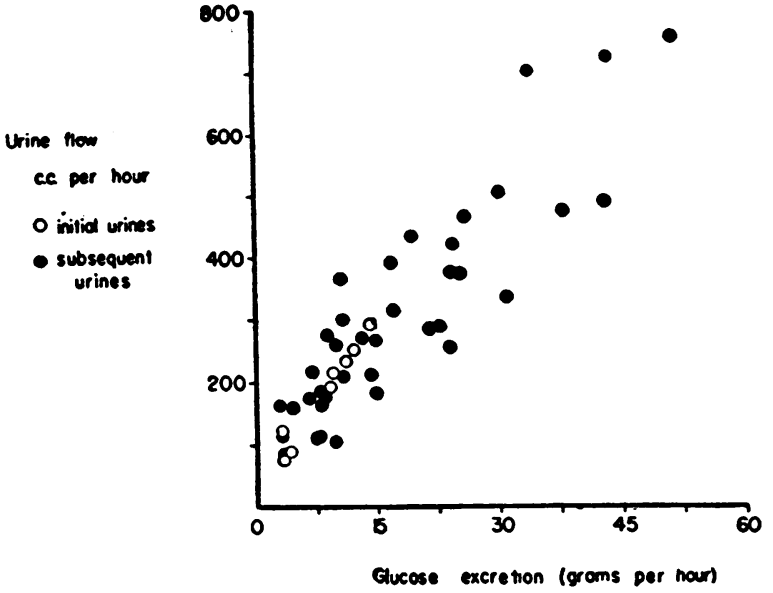

Fig. 1. The Relation of Urine Flow to the ExCREtion Rate of GLucose

$[\mathrm{Na}]-\left([\mathrm{Cl}]+\left[\mathrm{HCO}_{3}\right]+5\right)$, represents "potential bicarbonate" ( 5 meq. being subtracted for the average normal difference, $[\mathrm{Na}]-([\mathrm{Cl}]+$ $\left[\mathrm{HCO}_{3}\right]$ ) [26]). The values for the initial potential bicarbonate ranged from 18.3 to 30.0 meq./ liter, averaging 23.1. The average values of the bicarbonate plus potential bicarbonate are $23.1+$ $7.2=30.3$ meq./liter. It is thus apparent that the concentration of sodium available for combination with bicarbonate once carbohydrate metabolism is restored- $[\mathrm{Na}]-([\mathrm{Cl}]+5)$-is usually greater, rather than less, than normal.

The concentrations of sodium and chloride were normal in five patients; in the remaining five, moderate to extreme reductions in sodium were accompanied by proportionate (M.C., E.M., A.P.) or relatively greater (M.B., B.H.) reductions of chloride. Excessive deficits in the concentration of chloride probably result from the fact that contraction of the extracellular volume due to a loss of water in excess of salt elevates the concentration of sodium more than chloride, and account for the abnormally high concentrations of $\mathrm{HCO}_{3}$ plus potential bicarbonate, noted above in these patients.

In three patients (M.N., H.T., B.H.), all of whom were in shock, the serum potassium was slightly elevated (5.5 to 5.6 meq./liter); it was well within the normal range in M.B. (4.3 meq./ liter) despite the presence of complete anuria. The concentrations of serum phosphorus ranged from 2.80 to $10.1 \mathrm{mg}$. per cent. Abnormally high values were found only in patients in vascular col- lapse ; but one patient in vascular collapse (M.B.) had a normal serum phosphorus (4.25 mg. per cent). In two patients (B.K., W.R.) the initial serum phosphorus was slightly low.

Urine was collected before the institution of treatment from eight patients (Tables II and IV). Urine flows ranged from 77 to $292 \mathrm{cc}$./hour and were almost exactly proportional to the excretion of glucose, the ratio $\frac{\text { glucose gms./hour }}{\text { urine flow cc./hour }}$ averaging 0.047 gms./cc. (or $261 \mathrm{mM}$./liter), except for B.K. whose urine was even less concentrated. The reciprocal of 0.047 , the number of cc. of water commanded by each gram of glucose, is 21 , an indicaton of the profoundly dehydrating influence of glycosuria. More sodium than chloride was always excreted, the excess sodium presumably bound with ketones and undetermined acids (27, 28). High excretion rates of potassium, averaging 7.7 meq./hour, were present initially in all cases save E.M. The excretion of phosphorus, like that of potassium, was also accelerated initially, in keeping with previous reports $(27,29$ 31).

The metabolism of glucose. The extracellular and intracellular balances of carbohydrate for pa-

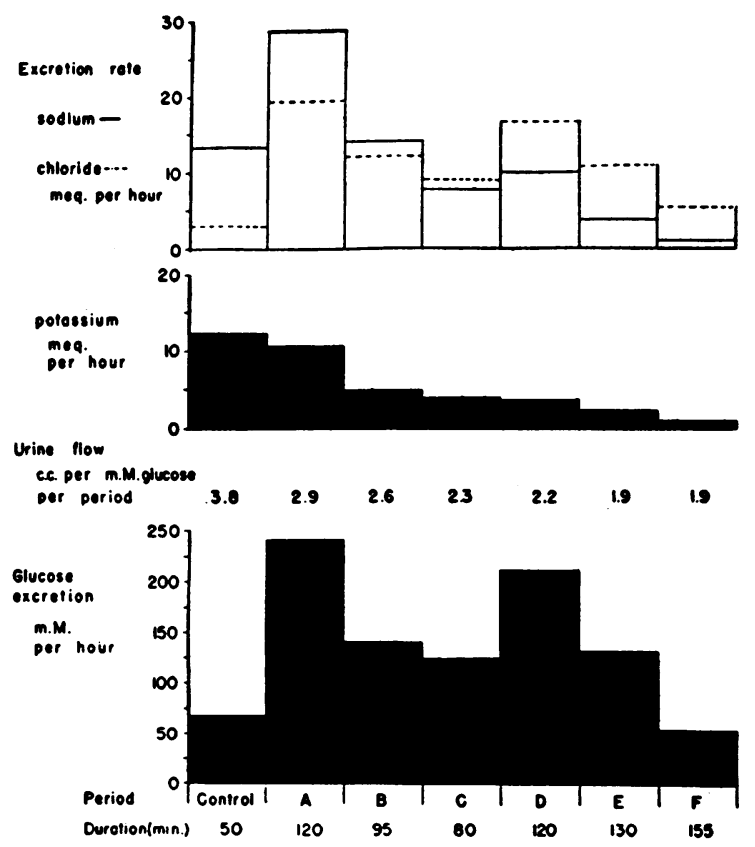

Fig. 2. The Relation of the Excretion Rate of Glucose to the Excretion of Water and ElectroLYTES IN R.R. 
tients given small or massive injections of glucose are listed in Tables III and IV, respectively. Within the first four hours of treatment, positive intracellular balances of glucose-i.e., the fractions of administered glucose which could be recovered neither in the extracellular fluid nor urine, and hence were presumably oxidized or stored-were observed in patients given small (Table III) or massive (Table IV) amounts of glucose. Since these balances were not corrected for endogenous glucose production (which, judging only from the rate of glucose excretion before treatment, varied from 3 to $14 \mathrm{gms}$./hour), it must be concluded that even in severe diabetic acidosis considerable amounts of carbohydrate can be utilized. The greatest utilization of carbohydrate within the first four hours of treatment, varying from 22 to 32 gms./hour, occurred in three cases of the group given massive injections of glucose (M.Be, $\mathrm{M}^{\mathrm{B}} \mathrm{Br}^{2}$, R.R., Table IV). Utilization of carbohydrate in the remaining four cases of this group was much slower, varying from 6 to $15 \mathrm{gms}$./hour. Those patients receiving small injections of glucose in the initial four hours of treatment utilized carbohydrate at a rate ranging from 3 to $18 \mathrm{gms}$./hour (Table III). In this group, also, utilization of exogenous glucose varied widely. For example, B.K., and A.F. ${ }^{1}$ received glucose at the rate of 19 and $25 \mathrm{gms}$./hour respectively in period A (Table I), but the former utilized almost all the administered glucose (18 gms./hour) while the latter utilized only 5 gms./hour (Table III). Apparently, the accelerating effect of carbohydrate intake on utilization is modified by as yet undefined factors, such as shock and dehydration. Of the fatal cases, where short early balance periods were available (H.T., M.B.), no glucose utilization could be demonstrated (Table III).

The excretion of water. Despite the presence of severe dehydration, urine flow was strikingly augmented in proportion to the magnitude of the glycosuria (Figure 1). Since patients given massive injections may excrete 50 per cent or more of the administered glucose, the resulting diuresis may be enormous (Table IV). Urine flow remained stationary or was accelerated only moderately in patients receiving small injections (Table II). In the case of R.R. (Table IV), repeated injections of glucose resulted in a progressive de- cline in the urine flow per gram of glucose from $21 \mathrm{cc} . / \mathrm{gm}$. at the beginning of the study to $11 \mathrm{cc}$./ gm. at the close. It is not clear whether this progressive conservation of water by the kidney is due to hypertonicity of the body fluids, a decreased excretion of total urinary solutes, or an increased efficiency in the reabsorption of water.

Excretion and transfer of sodium and chloride. Changes in the excretion of sodium and chloride correlated well, in the early periods of each individual case, with changes in the excretion of glucose (Tables II and IV). When the rate of glucose excretion rose from 12.1 to 43.4 gms./hour in R.R. (Table IV, periods Prt. and A), the excretion of sodium and chloride increased 15.3 and 16.6 meq./hour respectively from previous excretion rates of 13.4 meq./hour for sodium and 2.9 meq./hour for chloride. Glucose swept sodium into the urine as sodium chloride, as it does in normal human subjects (32) controlled diabetes (33) and animals (34). In the later periods of study in R.R. chloride was excreted in considerable excess of sodium, so that the excretion of chloride exceeded the sum of sodium plus potassium by almost 5 meq./hour. This dissociation probably represents a sparing of sodium in the restoration of acid-base equilibrium, with the excretion of increasing amounts of chloride probably as ammonium chloride, when serum bicarbonate is reconstituted during the recovery from acidosis. The fact that it occurs in R.R. where massive glycosuria prevailed throughout, as well as in the later periods of study in M.C., B.K., and W.R. (Table II), where glycosuria was relatively mild, indicates that the process is not inhibited by the renal osmotic effects of a glucose diuresis. The entire sequence of events is illustrated for R.R. in Figure 2.

The concentration of serum bicarbonate was below normal in all instances at the close of the study (Table II), and for an additional 24 hours in the case of E.M. and M.N. Since extracellular volume was no longer rapidly expanding and the concentration of serum sodium was in most instances normal or slightly elevated, the low bicarbonate cannot be ascribed to dilution or depression of fixed base (35). Hyperchloremia cannot account for the deficit, inasmuch as the difference between sodium and the sum of bicarbonate plus chloride 
was greater than 5 meq./liter, and therefore indicates the presence of excessive amounts of fixed acids in the serum. Although ketonuria (as judged by the qualitative nitroprusside test) was absent in B.K., A.F. ${ }^{1}$ and W.R. at the close of the study, and in E.M. and M.N. for 24 hours thereafter, it is possible that the fixed acids may represent a mild ketonemia of insufficient intensity to produce a ketonuria which could be detected by the nitroprusside test for acetone. It is also possible that the prolonged accumulation of undetermined acids, at least in certain instances where shock was present, may be partly due to a renal injury of the nature of a mild lower nephron nephrosis, as a consequence of which fixed acids (ketone bodies or other undetermined acids) might be retained. This interpretation is consistent with the impaired urea clearances and azotemia which have been noted by others (28) after recovery from diabetic acidosis.

The calculated transfers of sodium into and out of the extracellular fluid (which are usually interpreted as transfers to and from cells) were of small magnitude, slightly exceeding 100 meq. in only one instance, and fell into no discernible pattern (Table III). Since sodium is present principally in the extracellular fluid in high concentrations, small errors in the estimation of the chloride space and in the concentration of serum sodium could result in large calculated transfers of sodium. These data, therefore, cannot be interpreted to mean that the calculated movements represent actual transfers, although, of course, such a possibility is not excluded: Transfers of far greater magnitude have been reported by others $(36,37)$.

Expansion of extracellular volume, which gives a rough index of the extent of depletion before treatment, varied from 1.3 to 3.8 liters in six patients (Table III). (Fatal cases are not here considered because of the likelihood of over-expansion.) Since four of these six patients had normal concentrations of sodium and chloride initially, the latter cannot be considered a reliable guide to the volume of the extracellular fluids.

Excretion and transfer of potassium and phosphorus. The concentrations of serum potassium and phosphorus fell progressively during treatment, regardless of the initial concentrations, un- til exogenous supplies were available (Table II). This is in accord with previous reports $(30,31$, $37,38)$.

The excretion of potassium was greatest either before treatment was started or immediately thereafter, usually falling steadily, despite striking increases in glycosuria and urine flow (Tables II and IV). The changes in phosphorus excretion followed a similar course as others have noted (27, 30,31 ).

Table III lists the cellular balances of potassium and phosphorus. The discharge of potassium from cells was highest initially and fell during treatment. Although there was, perhaps, greater variability in this respect in the case of phosphorus, the same tendency was evident (Table III). The net cellular exchanges of potassium were positive in three patients (M.C., H.T., B.H.) and of phosphorus in six patients, prior to administration of either of these ions (Table III).

No specific clinical evidences of a low serum potassium were noted. However, deleterious consequences arising from a concentration of 1.8 meq./liter (Table II, A.P.) cannot be excluded, and emphasize the necessity of administering potassium earlier in treatment, before the serum concentration has fallen to such a low value. When potassium and phosphorus were given intravenously or orally, their serum concentrations rose and large increments were retained by cells (Table III). In one instance, however, excessive amounts of potassium may have been forced into cells. A deficit of potassium was apparently replenished by period D in A.F., when most of the administered potassium was rejected (Table I). Nevertheless, in period E, almost half of the large intake was retained. This retention of exogenous potassium after an initial rejection may have been in excess of cellular requirements. Although the serum potassium remained within normal limits (rising from 4.0 to 4.8 meq./liter), abnormal elevations in the serum concentration have resulted from the administration of large amounts of potassium in other studies (37).

\section{DISCUSSION}

Contraction of the extracellular volume in diabetic acidosis has long been recognized by such criteria as hemoconcentration $(27,39,40)$, in- 
creased concentration of serum proteins $(27,39$, 40), retention of administered salt (41), and expansion of the chloride space after treatment (37). Although the magnitude of the shrinkage of extracellular volume will obviously vary with the severity of the disease and the size of the patient, deficits of about 3 liters noted in this study emphasize the enormous depletion of extracellular salt and water in the average patient.

In the production of this salt depletion, vomiting and ketonuria play an important, though subsidiary, role. The severity of the salt depletion is not related to the severity of the vomiting. Some patients, such as E.M. and M.N. in the present study, gave no story of vomiting yet were greatly depleted, a finding noted by other observers (35). If ketonuria were chiefly responsible for the sodium lost with a 3-liter contraction of extracellular volume, the concentration of serum sodium and bicarbonate plus potential bicarbonate should suffer a greater relative reduction than chloride. But this is not the case. It is apparent from Table II that bicarbonate plus potential bicarbonate are well preserved regardless of whether the concentration of chloride is depressed or normal. The chloride is depressed when sodium is depressed, indicating a loss of sodium mainly as sodium chloride. Moreover, since there is four times more chloride than bicarbonate in the extracellular fluids, it is apparent that from the standpoint of contraction of extracellular volume as well as concentration, most of the sodium must have been lost as sodium chloride, not as sodium ketone. These findings are in accord with the observations of Peters and his associates (35) and Kydd (41).

The increased urinary losses of sodium chloride after massive injections of glucose (Table IV, Figure 2) and the correlation between the excretion of glucose and sodium in patients with only moderate glucosuria (Table I) suggest that the major part of the salt deficit arises because salt as well as water is swept into the urine with glucose. Although Gabrilove (42) has offered some evidence to the contrary, the correlation between the excretion of glucose and sodium chloride is also evident in the data of Atchley, Loeb, and their associates (29), and has been reproduced in animals (34), controlled diabetes (33) and normal human subjects (32) by injections of glucose. This ca- pacity of glucose to sweep salt into the urine is not inhibited by severe salt depletion and dehydration, although some tendency to spare sodium (probably in the restoration of acid-base equilibrium) is evident in the rising chloride and falling sodium excretion rates during the later periods of glucose administration.

Yet this augmentation of water and salt excretion by no means exhausts the impact of glucose on the volume of the extracellular fluids and the concentration of sodium salts. For example, when M.B. (Table II, period C) was rapidly given $50 \mathrm{cc}$. of 50 per cent glucose and an infusion of $750 \mathrm{cc}$. of 10 per cent glucose, the serum concentration of sodium and chloride fell from 116.9 to 87.5 and 91.6 to $71.1 \mathrm{meq}$./liter respectively. The greater fall of sodium than chloride (29.4 and 20.5 , respectively) is not the result of a transfer of some sodium into cells, but an effect of dilution, sodium suffering a greater depression than chloride because of its higher concentration in the serum. The amount of fluid injected was far too small, however, to cause this dilution. Urinary losses of salt played no part, since the patient was anuric. It is apparent, therefore, that the fall in the concentration of sodium and chloride must have been due to a movement of water out of cells in response to the osmotic pressure of glucose. Similarly in the case of M.C. (Table II, period B), when the blood sugar fell rapidly from 600 to 270 mg. per cent, the chloride space shrank from 11.2 to 10.6 liters, despite an intake of over 2 liters of fluid containing 123 meq. of sodium, of which 96 were retained. The contraction of extracellular volume, under these circumstances, is attributable to a shift of water into cells when the osmotic pressure of the extracellular fluid declined as a result of the fall in the blood sugar. Since the administered fluid was hypotonic with respect to salt, this shrinkage of extracellular volume explains the rise of 7 meq. in the concentration of serum sodium.

Such shifts of water into and out of cells in response to decreases and increases of blood sugar would not occur if glucose diffused freely through cellular membranes and came to a diffusion equilibrium. Free glucose must therefore be confined largely to the extracellular fluid, penetrating cells perhaps as glucose-6-phosphate (43). Simi- 
lar conclusions have been reached by others (1, 44). This interpretation is in accord with other lines of evidence: 1 ) the demonstration by direct analysis of skeletal and heart muscles in animals $(45,46)$ and skeletal muscle in man (47) that free glucose is largely confined to that fraction of the water of muscle which is extracellular;2) the inability of glucose in a perfusing medium to penetrate tissue slices of muscle or brain, as judged by changes in the weight or size of tissues $(48,49)$; 3 ) the movement of water into and out of cells (as judged by changes in the chloride space and the concentration of serum sodium) in response to decreases or increases of the blood sugar in diabetics (50) and normal human subjects (32).

Transfers of water are not the only means by which osmotic uniformity of the body fluids may be preserved when the osmotic pressure of the extracellular fluid varies. Evidence in normal human subjects suggests that the metabolism of glucose, if sufficiently accelerated, will increase the quantity of osmotically active constituents of cells, thereby preserving a uniform osmotic pressure, despite high blood sugars, without great shifts in water (32). In B.H., for example, the concentration of serum sodium rose from 110 to 135 meq./liter despite the persistence of extreme hyperglycemia, probably because most of the exogenous glucose was metabolized, judging from the marked fall in the concentration of serum phosphorus (Table II) and the high cellular balances of glucose (Table III). In contrast, the administered glucose in the case of M.B., where the serum sodium fell precipitously, remained extracellular. Such factors as these, in addition to marked external losses of water far in excess of salt, often mask the osmotic effects of glucose, and account for the normal electrolyte concentrations in some patients with severe diabetic acidosis.

The tonicity of the body fluids may be defined as the concentration of those substances which exert an effective osmotic pressure because they are restrained from penetrating cell membranes and therefore can alter the distribution of water between the intracellular and extracellular phases. Substances such as urea, although contributing to the osmotic pressure or osmolarity of the extracellular fluids, have no effect on tonicity (as here defined), because they diffuse freely into body cells and hence do not influence the distribution of water. Under ordinary circumstances tonicity is almost completely determined by the concentration of sodium salts. When hyperglycemia supervenes, however, a large increment of the effective osmotic pressure is determined by the concentration of glucose in the extracellular fluid. It is apparent from Table II that, regardless of the concentration of serum sodium, the extracellular fluids were hypertonic initially in all cases. The lowest initial serum concentration of sodium was 105 meq./liter (M.B.); this is not a sign of hypotonicity, however, since the presence of about $93 \mathrm{mM}$. of glucose per liter of blood increased the effective osmotic pressure above the normal range. Similarly, where hyperglycemia is significant, normal concentrations of sodium and chloride in the serum must be considered evidences of hypertonicity. The magnitude of cellular dehydration in diabetic acidosis must therefore be extreme. Since hypertonicity of the extracellular fluids prevails before treatment, it follows that as hyperglycemia recedes water will move into cells, resulting in a tendency toward shrinkage of extracellular volume and probably an excessive rise in the concentration of sodium salts. To prevent this impediment to cellular hydration water must be administered in excess of normal saline.

The effective osmotic pressure of glucose accounts, in part at least, for the preponderance of low concentrations of serum sodium which are found in most patients with diabetic acidosis. It should be noted that the fluid lost during the development of diabetic acidosis (except for vomitus) is greatly hypotonic with respect to sodium chloride. The urine formed contains sodium at a concentration considerably below that of serum because glycosuria accelerates to a greater extent the excretion of water than of salt. Insensible perspiration and sweat are both hypotonic; hyperventilation results in the loss of water alone. Because of these losses of water in excess of salt, an elevated concentration of serum sodium and chloride might be anticipated, but this is rare. Probably cellular water, drawn into the extracellular compartment by extracellular hypertonicity resulting from high blood sugars, acts as a diluent, reducing the con- 
centration of sodium and chloride to normal or more often low values.

The clinical effects of cellular dehydration per $s e$ have not been precisely defined. Hypertonicity, despite the cellular desiccation it produces, would seem to favor an increased urine flow by expanding the extracellular volume and correcting an already contracted blood volume. Such an effect was not observed in M.Be (Table IV), however. The administration of $150 \mathrm{gms}$. of glucose when the blood sugar was $532 \mathrm{mg}$. per cent, accelerated urine flow by $200 \mathrm{cc}$./hour, while the N.P.N. fell $23 \mathrm{mg}$. per cent. When the blood sugar was $842 \mathrm{mg}$. per cent, a second injection of $125 \mathrm{gms}$. of glucose was accompanied by a fall in urine flow from 466 to $169 \mathrm{cc}$./hour, while the blood sugar rose to $1036 \mathrm{mg}$. per cent and the N.P.N. did not change. This reduction in urine flow despite the enormous glucose load could not be ascribed to dehydration because the patient was in positive water and salt balance. Although Winkler and his associates were unable to produce vascular collapse by hypertonicity alone (51), it is possible that profound dehydration of cells may aggravate the vascular insufficiency of an already impaired circulation.

These osmotic properties of glucose, increasing urinary losses of salt and water and dehydrating body cells, sharply delimit the extent to which the accelerating action of hyperglycemia on carbohydrate metabolism can be employed. It is apparent, however, from these studies that small or moderate amounts of exogenous glucose can be utilized early in severe diabetic acidosis without augmenting the hyperglycemia or producing undue glycosuria (Table II). Massive injections induce an intense hyperglycemia and glycosuria, but do not regularly augment the utilization of carbohydrate beyond that accomplished by small doses.

Although the profound alterations in the concentration of serum potassium are probably connected in part at least with changes in carbohydrate metabolism, the present study does not support the view (52) that glycosuria as a result of the administration of exogenous glucose plays an important role in this process by sweeping potassium into the urine. The excretion of potassium was highest initially and usually fell progressively notwithstanding marked increases in glycosuria.
The elevated serum concentration before treatment results from the failure of this initially accelerated loss by renal excretion and vomiting to keep pace with the effects of rapid cellular release of the ion (probably a consequence of dehydration and increased breakdown of glycogen and protein) and a contracting extracellular volume. After the institution of treatment, serum potassium fell steadily as extracellular volume expanded and renal losses continued (though at a slower rate). It has been demonstrated in normal human subjects (32) and animals (53) that expansion of extracellular volume per se does not proportionately depress the concentration of potassium because the rate of discharge from cells, which seems geared to maintain a constant serum concentration, becomes accelerated; but when glucose is given the serum potassium may fall, irrespective of changes in extracellular volume, because of a movement of potassium into cells associated with accelerated utilization and storage of carbohydrate. It is this progressive retardation of the release of cellular potassium, as dehydration and carbohydrate and protein breakdown are ameliorated, that prevents cellular stores from liberating sufficient potassium to compensate for the effects of dilution and renal loss. That exogenous glucose may promote a transfer of potassium into cells, and thereby hasten the fall of the serum concentration, must be admitted, but this hardly constitutes a valid objection to the use of glucose, since the acceleration of efficient utilization of carbohydrate is one of the central aims of therapy, and any measure which accomplishes this, including insulin, may have such an effect.

The metabolic and osmotic properties of glucose, here discussed, have important implications for treatment. It is clear that the marked losses of salt with glycosuria are accompanied by far greater losses of water. As a consequence, contraction as well as hypertonicity of the extracellular fluids ensue. The magnitude of the total water deficit may be underestimated because the effective osmotic pressure of glucose causes a dilution of the extracellular fluid with cell water, resulting in a normal or low, instead of elevated, concentration of serum sodium. Normal saline is required to expand extracellular volume. Glucose solution, since it affords a medium for the parenteral administration of water without salt, is necessary to 
ameliorate hypertonicity. Reliance on large quantities of normal saline as the major parenteral repair solution has resulted (37) in the development of excessively high concentrations of serum sodium and chloride as hyperglycemia receded with treatment. Most of the objections to glucose are really directed against the use of excessive amounts. The striking diuresis and marked exaggeration of cellular dehydration, noted in this study and elsewhere $(1,2)$, and the augmentation of urinary losses of salt, constitute valid reasons against the use of large injections. But small to moderate amounts of glucose may be employed without these consequences. The exogenous glucose which is utilized spares endogenous carbohydrate and retards ketosis, at the same time liberating water which can diffuse into cells and ameliorate dehydration. Where diabetic acidosis is particularly severe and hyperglycemia marked (i.e., over $700 \mathrm{mg}$. per cent) it is questionable whether an increased rate of utilization of carbohydrate can be promoted by raising the blood sugar still further (10), but such a procedure would almost certainly exaggerate the deleterious osmotic effects of glucose. Moreover, if the exogenous carbohydrate is not burned, the injected water cannot diffuse into cells and mitigate cellular dehydration. Under these circumstances, 5 per cent glucose in distilled water given intravenously at a rate in accord with the clinical and chemical status of the patient would seem a better vehicle than more concentrated glucose solutions. After the early hours of treatment, when the utilization of glucose becomes accelerated and hyperglycemia recedes, the danger of hypoglycemia appears, making the need for glucose more urgent. At this time, 10 per cent glucose, given at a rate of $250 \mathrm{cc}$./hour or more, seems advisable. These comments on glucose should not, of course, distract attention from the prior importance of insulin, normal saline, and blood, the necessity for which all investigators admit.

\section{SUM MARY AND CONCLUSIONS}

1. Seventeen cases of diabetic acidosis, studied during the early stages of the treatment of the disorder, received moderate or massive injections of glucose. Utilization of carbohydrate occurred within the first two to four hours of treatment, since the injected glucose could not be completely recovered in the urine or extracellular fluid.

2. Glycosuria swept out sodium chloride as well as water in large amounts, and is probably the major cause of salt depletion and dehydration in diabetic acidosis.

3. Evidence is presented suggesting that glucose is confined to the extracellular fluid. Hyperglycemia, therefore, draws water out of cells, producing cellular dehydration and diluting the serum sodium and chloride. This is probably a major cause of the low concentrations of sodium in the serum, and masks the magnitude of the total water deficit.

4. Because of the deleterious consequences of hypertonicity and cellular dehydration, the importance of glucose solution as a vehicle for the administration of water without salt is stressed.

5. Glycosuria resulting from injections of exogenous glucose does not sweep potassium into the urine. The mechanism responsible for the initial elevation and subsequent depression of the serum potassium is discussed.

The authors wish to express their appreciation to Miss Pauline M. Hald for advice and guidance in analytical techniques.

\section{BIBLIOGRAPHY}

1. Franks, M., Berris, R. F., Kaplan, N. O., and Myers, G. B., Metabolic studies in diabetic acidosis. I. The effect of the early administration of dextrose. Arch. Int. Med., 1947, 80, 739.

2. Lee, J., Naidoo, D., and Torrens, J. A., Diabetic coma. Treatment with and without the early administration of glucose. Brit. M. J., 1949, 1, 565.

3. Himsworth, H. P., The role of glucose in the treatment of diabetic intoxication. Lancet, 1932, 2, 165.

4. Lawrence, R. D., Treatment of diabetic coma. Brit. M. J., 1936, 2, 81.

5. Soskin, S., and Levine, R., Physiological and clinical aspects of ketosis. Am. J. Digest. Dis., 1944, 11, 305.

6. Peters, J. P., Starvation diabetes, the reason for the use of glucose in the treatment of diabetic acidosis. Yale J. Biol. \& Med., 1945, 17, 705.

7. Peters, J. P., The use of carbohydrate in diabetic acidosis. Am. J. Digest. Dis., 1946, 13, 127.

8. Conn, J. W., and Bauer, J. M., The administration of glucose in the treatment of diabetic coma; preliminary report. Univ. Hosp. Bull., Ann Arbor, 1945, 11, 49.

9. Mirsky, I. A., Franzblau, A. N., Nelson, N., and Nelson, W. E., The role of excessive carbohydrate intake in the etiology of diabetic coma. J. Clin. Endocrinol., 1941, 1, 307. 
10. Wierzuchowski, M., The limiting rate of assimilation of glucose introduced intravenously at constant speed in the resting dog. J. Physiol., 1936, 87, 311.

11. Wierzuchowski, M., Oxidation of glucose as function of its supply. J. Physiol., 1937, 90, 440.

12. Mirsky, I. A., Heiman, J. D., and Broh-Kahn, R. H., The antiketogenic action of glucose in the absence of insulin. Am. J. Physiol., 1937, 118, 290.

13. Soskin, S., and Levine, R., A relationship between the blood sugar level and rate of sugar utilization, affecting the theories of diabetes. Am. J. Physiol., 1937, 120, 761.

14. Klatskin, G., The response of diabetics to a standard test dose of insulin. J. Clin. Invest., 1938, 17, 745.

15. Benedict, S. R., The estimation of sugar in blood and normal urine. J. Biol. Chem., 1926, 68, 759.

16. Somogyi, M., A method for the preparation of blood filtrates for the determination of sugar. J. Biol. Chem., 1930, 86, 655.

17. Somogyi, M., A new reagent for the determination of sugars. J. Biol. Chem., 1945, 160, 61.

18. Fiske, C. H., and Subbarow, Y., The colorimetric determination of phosphorus. J. Biol. Chem., 1925, 66, 375 .

19. Elkinton, J. R., and Taffel, M., Prolonged water deprivation in the dog. J. Clin. Invest., 1942, 21, 787.

20. Hald, P. M., The flame photometer for the measurement of sodium and potassium in biological materials. J. Biol. Chem., 1947, 167, 499.

21. Elkinton, J. R., and Winkler, A. W., Transfers of intracellular potassium in experimental dehydration. J. Clin. Invest., 1944, 23, 93.

22. Elkinton, J. R., Winkler, A. W., and Danowski, T. S., Transfers of cell sodium and potassium in experimental and clinical conditions. J. Clin. Invest., 1948, 27, 74.

23. Darrow, D. C., The retention of electrolytes during recovery from severe dehydration due to diarrhea. J. Pediat., 1946, 28, 515.

24. Pareira, M. D., and Somogyi, M., Rationale of parenteral glucose feeding in the postoperative state. Ann. Surg., 1948, 127, 417.

25. Collen, M. F., Mortality in diabetic coma. Arch. Int. Med., 1942, 70, 347.

26. Hald, P. M., Heinsen, A. J., and Peters, J. P., The estimation of serum sodium from bicarbonate plus chloride. J. Clin. Invest., 1947, 26, 983.

27. Bulger, H. A., and Peters, J. P., The concentration of the blood and of the urine in diabetic toxemia. Arch. Int. Med., 1925, 36, 857.

28. McCance, R. A., and Lawrence, R. D., The secretion of urine in diabetic coma. Quart. J. Med., 1935, 4, 53.

29. Atchley, D. W., Loeb, R. F., Richards, D. W., Jr., Benedict, E. M., and Driscoll, M. E., On diabetic acidosis. A detailed study of electrolyte balances following withdrawal and reestablishment of insulin therapy. J. Clin. Invest., 1933, 12, 297.
30. Guest, G. M., Organic phosphates of the blood and mineral metabolism in diabetic acidosis. Am. J. Dis. Child., 1942, 64, 401.

31. Franks, M., Berris, R. F., Kaplan, N. O., and Myers, G. B., Metabolic studies in diabetic acidosis. II. The effect of the administration of sodium phosphate. Arch. Int. Med., 1948, 81, 42.

32. Seldin, D. W., and Tarail, R., The effect of hypertonic solutions on the metabolism and excretion of electrolytes. Am. J. Physiol., 1949, 159, 160.

33. Rapoport, S., West, C. D., and Brodsky, W. A., Excretion of solutes and osmotic work during osmotic diuresis of hydropenic man. The ideal and the proximal and distal tubular work; the biological maximum of work. Am. J. Physiol., 1949, 157, 363.

34. Kerpel-Fronius, E., Zur Frage des diabetischen Salzmangelzustandes. Klin. Wchnschr., 1937, 16, 1466.

35. Peters, J. P., Kydd, D. M., and Eisenman, A. J., The nature of diabetic acidosis. J. Clin. Invest., 1933, 12, 377.

36. Butler, A. M., Talbot, N. B., Burnett, C. H., Stanbury, J. B., and MacLachlan, E. A., Metabolic studies in diabetic coma. Tr. A. Am. Physicians, 1947, 60, 102.

37. Danowski, T. S., Peters, J. H., Rathbun, J. C., Quashnock, J. M., and Greenman, L., Studies in diabetic acidosis and coma, with particular emphasis on the retention of administered potassium. J. Clin. Invest., 1949, 28, 1.

38. Martin, H. E., and Wertman, M., Serum potassium, magnesium and calcium levels in diabetic acidosis. J. Clin. Invest., 1947, 26, 217.

39. Hartmann, A. F., and Darrow, D. C., Chemical changes occurring in the body as the result of certain diseases. III. The composition of the plasma in severe diabetic acidosis and the changes taking place during recovery. J. Clin. Invest., 1928, 6, 257.

40. Peters, J. P., Kydd, D. M., and Eisenman, A. J., Serum proteins in diabetic acidosis. J. Clin. Invest., 1933, 12, 355.

41. Kydd, D. M., Salt and water in the treatment of diabetic acidosis. J. Clin. Invest., 1933, 12, 1169.

42. Gabrilove, J. L., Chloride excretion during glycosuria in patients with diabetes. J. Clin. Invest., 1946, $25,256$.

43. Sacks, J., Radioactive phosphorus studies on hexosemonophosphate metabolism in resting muscle. Am. J. Physiol., 1944, 142, 145.

44. Somogyi, M., Studies of arteriovenous differences in blood sugar. I. Effect of alimentary hyperglycemia on the rate of extrahepatic glucose assimilation. J. Biol. Chem., 1948, 174, 189.

45. Cori, G. T., Closs, J. O., and Cori, C. F., Fermentable sugar in heart and skeletal muscle. J. Biol. Chem., 1933, 103, 13.

46. Eggleton, M. G., Diffusion of sugars into muscle. J. Physiol., 1935, 84, 59P. 
47. Trimble, H. C., and Cary, B. W., Jr., On the true sugar content of skin and of muscle in diabetic and non-diabetic persons. J. Biol. Chem., 1931, 90, 655.

48. Fenn, W. O., Electrolytes in muscle. Physiol. Rev., 1936, 16, 450.

49. Elliott, K. A. C., Swelling of brain slices and the permeability of brain cells to glucose. Proc. Soc. Exper. Biol. \& Med., 1946, 63, 234.

50. Sunderman, F. W., The water and electrolyte distribution in diabetes mellitus; dehydration in diabetes. Am. J. M. Sc., 1943, 205, 102.

51. Winkler, A. W., Elkinton, J. R., Hopper, J., Jr., and
Hoff, H. E., Experimental hypertonicity: alterations in the distribution of body water, and the cause of death. J. Clin. Invest., 1944, 23, 103.

52. Joslin, E. P., Root, H. F., White, P., and Baily, A. C., The Treatment of Diabetes Mellitus. Lea \& Febiger, Philadelphia, 1946.

53. Elkinton, J. R., Winkler, A. W., and Danowski, T. S., The importance of volume and of tonicity of the body fluids in salt depletion shock. J. Clin. Invest., 1947, 26, 1002.

54. McCance, R. A., and Widdowson, E. M., The Chemical Composition of Foods. Chemical Publishing Co., Brooklyn, 1947. 